\title{
Aircraft type influence on contrail properties
}

\author{
P. Jeßberger ${ }^{1,2}$, C. Voigt ${ }^{1,2}$, U. Schumann ${ }^{1}$, I. Sölch ${ }^{1}$, H. Schlager ${ }^{1}$, S. Kaufmann ${ }^{1,2}$, A. Petzold ${ }^{1, *}$, D. Schäuble ${ }^{1,{ }^{* *}}$, and \\ J.-F. Gayet ${ }^{3}$ \\ ${ }^{1}$ Deutsches Zentrum für Luft- und Raumfahrt, Institut für Physik der Atmosphäre, Oberpfaffenhofen, Germany \\ ${ }^{2}$ Johannes-Gutenberg-Universität, Institut für Physik der Atmosphäre, Mainz, Germany \\ ${ }^{3}$ University Blaise Pascal, LaMP, Clermont - Ferrand, France \\ *now at: Forschungszentrum Jülich, Institut für Energie- und Klimaforschung, Jülich, Germany \\ ** now at: Institute for advanced sustainability studies, Potsdam, Germany \\ Correspondence to: P. Jeßberger (philipp.jessberger@dlr.de)
}

Received: 5 March 2013 - Published in Atmos. Chem. Phys. Discuss.: 27 May 2013

Revised: 12 November 2013 - Accepted: 13 November 2013 - Published: 11 December 2013

\begin{abstract}
The investigation of the impact of aircraft parameters on contrail properties helps to better understand the climate impact from aviation. Yet, in observations, it is a challenge to separate aircraft and meteorological influences on contrail formation. During the CONCERT campaign in November 2008, contrails from 3 Airbus passenger aircraft of types A319-111, A340-311 and A380-841 were probed at cruise under similar meteorological conditions with in situ instruments on board DLR research aircraft Falcon. Within the 2 min-old contrails detected near ice saturation, we find similar effective diameters $D_{\text {eff }}(5.2-5.9 \mu \mathrm{m})$, but differences in particle number densities $n_{\text {ice }}\left(162-235 \mathrm{~cm}^{-3}\right)$ and in vertical contrail extensions (120-290 m), resulting in large differences in contrail optical depths $\tau$ at $550 \mathrm{~nm}(0.25-0.94)$. Hence larger aircraft produce optically thicker contrails.

Based on the observations, we apply the EULAG-LCM model with explicit ice microphysics and, in addition, the Contrail and Cirrus Prediction (CoCiP) model to calculate the aircraft type impact on young contrails under identical meteorological conditions. The observed increase in $\tau$ for heavier aircraft is confirmed by the models, yet for generally smaller $\tau$. CoCiP model results suggest that the aircraft dependence of climate-relevant contrail properties persists during contrail lifetime, adding importance to aircraftdependent model initialization. We finally derive an analytical relationship between contrail, aircraft and meteorological parameters. Near ice saturation, contrail width $\times \tau$ scales linearly with the fuel flow rate, as confirmed by observations. For higher relative humidity with respect to ice (RHI), the analytical relationship suggests a non-linear increase in the
\end{abstract}

form (RHI-1 $)^{2 / 3}$. Summarized, our combined results could help to more accurately assess the climate impact from aviation using an aircraft-dependent contrail parameterization.

\section{Introduction}

Aircraft contrails affect climate by reflection of incoming solar radiation and trapping of outgoing terrestrial radiation. Thereby the global net effect results in a warming of the atmosphere (Fahey et al., 1999). A common metric for the quantification of the climate impact from contrails is contrail radiative forcing $(\mathrm{RF})$, the difference between the radiative fluxes at the tropopause of two atmospheric scenarios with and without contrails. Minnis et al. (1999) derived a best estimate for the contrail radiative forcing from air traffic in 1992 of $20 \mathrm{~mW} \mathrm{~m}^{-2}$ based on an analysis of traffic data, meteorological data and satellite observations. Lee et al. (2009) extrapolated previous estimates of contrail radiative forcing to the 2005 air traffic $\left(11.8 \mathrm{~mW} \mathrm{~m}^{-2}, 90 \%\right.$ likelihood range: $5.4-25.6 \mathrm{~mW} \mathrm{~m}^{-2}$ ). Recently, Voigt et al. (2011) estimated a radiative forcing of linearly shaped contrails of $15.9 \mathrm{~mW} \mathrm{~m}^{-2}\left(11.1-47.1 \mathrm{~mW} \mathrm{~m}^{-2}\right)$ using extended in situ observations. The total climate effect of contrail cirrus including linear and persistent contrails is likely larger and may range from 30 to $80 \mathrm{~mW} \mathrm{~m}^{-2}$ (Burkhardt and Kärcher, 2011). Schumann and Graf (2013) derive a global net RF of about 50 (40-80) $\mathrm{mW} \mathrm{m}^{-2}$ from observations and models for a shortwave/longwave RF-magnitude ratio of 0.6 with possibly larger net RF for smaller ratios. Hence contrail cirrus 
globally contribute $\approx 3-5 \%$ to the total anthropogenic radiative forcing of $1.6 \mathrm{~W} \mathrm{~m}^{-2}$ (Solomon et al., 2007). Local effects can be significantly larger (Burkhardt and Kärcher, 2011; Graf et al., 2012) and the level of scientific understanding is still assessed as low to very low (Lee et al., 2009). The climate impact of contrails depends on contrail cover and optical depth (Meerkötter et al., 1999), solar and earth radiation, microphysical and atmospheric parameters, some of which are aircraft dependent.

The altitude range where contrails form is mainly controlled by ambient temperature and humidity and by aircraft fuel properties (water vapour emission index and specific combustion heat) (Schumann, 1996), with a weak influence of the overall propulsion efficiency of the aircraft-engine combination (Schumann, 2000; Schumann et al., 2000). At the high relative humidity during contrail formation, the engine exhaust plume contains an aerosol of non-volatile (mainly soot) and volatile particles from condensing particle precursors (sulphuric acid, organic acids) and part of this aerosol gets activated and liquid droplets form which then freeze and form ice particles (Kärcher and Yu, 2009). Ice nucleation takes place in the exhaust jets within a wing-span behind the aircraft or earlier, depending on ambient temperature. Later during the jet phase, depending on aircraft parameters, the airflow above the wings transforms into a counterrotating vortex pair (Paoli et al., 2003), in which the exhaust material behind each engine is entrained (Gerz and Ehret, 1997). The two vortices propagate downwards by mutual induction of velocity, and take most of the exhaust material with them. The air in the vortex core is heated by adiabatic compression (Greene, 1986). This heating decreases the relative humidity, eventually resulting in a partial sublimation of the ice crystals. During downward movement a fraction of the exhaust is detrained from the vortex pair and parts may propagate upwards by buoyancy to the original emission level, thereby mixing with the exhaust that has not been captured by the vortex pair and building a secondary wake regime. Under ice supersaturated conditions the detrained ice particles grow further by uptake of ambient water vapour (Unterstrasser and Sölch, 2010). Ice crystal number densities and sizes can vary in the primary vortices and the secondary wake (Gayet et al., 2012). After the breakup of the vortex structures, initiated from small disturbances by the Crow instability or from ambient turbulence (Misaka et al., 2012), the contrail spreads out and disperses depending on atmospheric wind shear and turbulence (Jensen et al., 1998). Contrails may survive for several hours in ice supersaturated conditions (Graf et al., 2012), with the total contrail cover being dependent on air traffic movement and distribution. The contrail lifetime depends further strongly on the microphysical properties of the contrail particles. Hence, contrail properties depend on many atmospheric and aircraft parameters, which are known to different degrees.

Microphysical and dynamical properties of contrails at various ages have been measured and modelled in several studies (Heymsfield et al., 2010). In situ measurements in young contrails are challenging because of strong turbulence in the aircraft wake. However, such measurements provide insight into ice particle concentrations, ice particle sizes, and ice particle habits as required to derive the optical parameters (Petzold et al., 1997; Baumgardner and Gandrud, 1998; Poellot et al., 1999; Schröder et al., 2000; Gao et al., 2006; Voigt et al., 2010; Jones et al., 2012). Optical depths of 0.15 and 0.25 have been derived from measurements in two 10 and 20 min-old Embraer-170 contrails (Febvre et al., 2009). At an age of $3 \mathrm{~min}$ at ice supersaturated conditions, the contrail had an optical extinction of $0.48 \mathrm{~km}^{-1}$. Voigt et al. (2011) derived a mean (median) contrail optical depth of 0.27 (0.13) from 14 young $<5$ min-old contrails near ice saturation of nine different aircraft. Satellite observations of contrail optical depth concentrate on older contrails (Iwabuchi et al., 2012), as the detection efficiency for young contrails with widths less than a few $100 \mathrm{~m}$ is limited.

Lidar observations combined with numerical studies by Sussmann and Gierens $(1999,2001)$ suggest that early contrail properties depend on atmospheric conditions as well as on the aircraft type. While a clear separation of the primary and secondary wakes has been detected in the contrail of a four-engine aircraft, with the secondary vortex becoming persistent in most cases, this separation has not been observed for two-engine aircraft. Lewellen and Lewellen (2001) calculate the sensitivity of the fraction of the surviving ice crystals, the total ice crystal surface area and the ice mass distribution on the aircraft type and ambient relative humidity with respect to ice (RHI). Naiman et al. (2011) perform large eddy simulations to investigate the influence of meteorological parameters and aircraft type on contrail optical depth and coverage, with variations in the aircraft type resulting in variations in optical depth between $20 \%$ to $50 \%$ with respect to the baseline. Simulations by Unterstrasser and Gierens (2010) show that contrail evolution in the vortex phase affects contrail optical properties and the lifetime of contrail cirrus over hours.

While several modelling results suggest an aircraft effect on contrail formation, atmospheric variability previously prevented a direct comparison of contrail properties from different aircraft. Here we investigate in detail three data sequences from in situ observations in 2 min-old contrails from A319-111, A340-311 and A380-841 aircraft, detected on 19 November 2008 under similar meteorological conditions with research aircraft Falcon above northern Germany during the CONCERT campaign (Voigt et al., 2010). Differences in particle size distributions, number densities, contrail vertical depth and optical depth are evaluated. We compare the results with two model studies performed with the EULAG-LCM Lagrangian particle tracking model (Sölch and Kärcher, 2010) and the contrail cirrus prediction model (CoCiP) (Schumann, 2012) to identify the aircraft influence on contrail properties under identical meteorological fields. The CoCiP model will also be used to show that the contrail 
properties in young contrails (of order $2 \mathrm{~min}$ ) are of importance for the climate impact of contrails over the whole lifetime of the contrails. We analytically derive a relationship between aircraft parameters, meteorological parameters and critical cloud microphysical parameters. We find that the fuel consumption per unit flight path linearly scales with the total extinction, the product of contrail optical depth and horizontal width. We further parameterize the dependence of the total extinction on RHI based on approximations from theory. We compare our findings with our observations and previous measurements and model results.

\section{Instrumentation}

During the CONCERT campaign the DLR research aircraft Falcon-20E5 was equipped with a set of instruments to measure microphysical and optical contrail properties together with some chemical properties (Voigt et al., 2010). A description of the instrumentation is given in Voigt et al. (2010); individual instruments are discussed in detail by Jurkat et al. (2010), Schmale et al. (2010), Kübbeler et al. (2011) and Gayet et al. (2012). Here, we only describe instruments of relevance to this work.

\subsection{The FSSP-300 forward scattering spectrometer probe}

The FSSP-300 forward scattering spectrometer probe (Baumgardner et al., 1992; Petzold et al., 1997) mounted in the right wing station of the Falcon detects the amount of light scattered by a single particle in forward directions at angles from $6^{\circ}$ to $15^{\circ}$. The amount of scattered light thus depends on the particle size, shape and refractive index. The signal is resolved into an array of 31 channels, which have been calibrated prior to the flight. For the calibration, monodisperse polystyrene latex spheres have been used to calibrate the channels, detecting particles $\geq 1 \mu \mathrm{m}$. The smaller size channels were calibrated using sebacate oil droplets. The signal is then converted into a corresponding particle size using the refractive index of $1.31+0.0 i$ of ice. We assume that all ice particles in the young contrails have a quasi-spherical shape. This simplifying hypothesis is confirmed by comparing FSSP-300 results with polar nephelometer (PN) observations in the A380 contrail (Gayet et al., 2012). Best agreement between the extinction derived with two independent methods is achieved assuming initially quasi-spherical ice crystals and the fraction of nonspherical particles increasing with contrail age. At contrail ages $<2 \mathrm{~min}, 80$ to $100 \%$ of the particles are quasi-spherical (Gayet et al., 2012, their Fig. 5). In the case of existing nonspherical particles, the derived surface areas might be overestimated (Borrmann et al., 2000); however, this effect is expected to be small for young contrails.
In the current study channels 1 and 9 are excluded due to instrumental noise, and channels 30 and 31 are excluded due to overcounting effects caused by high ice particle concentrations in young contrails. The channels 10-15, 16$18,19-21,22-23,24-25,26-29$ are grouped in order to avoid ambiguities in the probe response function due to Mie scattering theory (Baumgardner et al., 1989). This results in 13 binned size channels for particle diameters between $0.49 \mu \mathrm{m}<D<17.97 \mu \mathrm{m}$. Uncertainties in the FSSP-300 data are caused by errors in the particle sizing and uncertainties in the number concentration at low sampling statistics or very high particle concentrations. The optical sampling area of our instrument was $0.188 \mathrm{~mm}^{2}$, leading to a sampling volume of $38 \mathrm{~cm}^{3}$ at a typical aircraft speed of $200 \mathrm{~m} \mathrm{~s}^{-1}$. The number concentration in the contrail is typically of the order of several $100 \mathrm{~cm}^{-3}$, and each contrail is sampled and averaged for more than $60 \mathrm{~s}$, therefore errors due to counting statistics are small for $D<10 \mu \mathrm{m}$. Effects of particles bouncing off the inlet walls of particle probes have been discussed in detail by Korolev et al. (2013). This effect may lead to an overestimation of the particle number densities. Coincidence effects eventually caused by particle bouncing may result in a broadening of the particle size distribution (Cooper, 1988). The extinction data from the polar nephelometer and the FSSP-300 with different inlet geometries are consistent (Gayet et al., 2012), and hence suggest that inlet artefacts are also small at high particle number concentrations. For particle number concentrations less than $500 \mathrm{~cm}^{-3}$, which is higher than the observed particle number concentrations, the errors due to coincidence losses are below $5 \%$ (Baumgardner et al., 1992). Still, we cannot completely exclude that particle bouncing may occur.

As discussed by Voigt et al. (2011), our FSSP-300 was not equipped with techniques to correct for artificially enhanced ice crystal concentrations caused by shattering of large ice crystals on protruding probe inlets (McFarquhar et al., 2007). Still, the contrails were observed in clear sky or subvisible cirrus, hence large particles were present in very low concentrations, if at all. The comparison with cirrus observations nearby suggests that the ice crystal concentration in contrails is affected at less than $1 \%$ by ambient cirrus (Voigt et al., 2011, their Fig. 2). A similar analysis has been performed for the present study.

\subsection{The Polar Nephelometer}

Additionally, the Falcon was equipped with a polar nephelometer (PN) (Gayet et al., 1997) mounted on the left wing station. The PN measures the scattering phase function of cloud particles which intersect a collimated laser beam $(\lambda=804 \mathrm{~nm})$ near the focal point of a parabolic mirror. For very small particles, the sampling efficiency is low due to small optical active surfaces (Gayet et al., 2012), therefore only ensemble values can be measured by a longer integration interval. Under the assumption of randomly orientated, 
non-absorbing ice particles, integrated optical parameters such as the extinction coefficient and asymmetry parameters can also be calculated (Gayet et al., 2002). The accuracy of the extinction is $25 \%$ (Gayet et al., 2012).

\subsection{Hygrometers}

Water vapour mixing ratios were simultaneously measured by the closed-path Fast In situ Stratospheric Hygrometer (FISH) and the frost point CR-2 hygrometer (Buck Research Instruments, LLC). The FISH instrument was developed at the Jülich Research Centre and is based on the Lyman- $\alpha$ photofragment fluorescence technique with a measurement frequency of $1 \mathrm{~Hz}$ (Schiller et al., 2008; Kübbeler et al., 2011). In combination with a backward-facing inlet, only gas phase water vapour was sampled inside and outside of ice clouds. For the calculation of the relative humidity, the air temperature $T$ is needed. The temperature measured onboard the Falcon is used. The uncertainties are $\pm 0.5 \mathrm{~K}$ for temperature, $\pm 0.5 \mathrm{hPa}$ for pressure, and $\pm 6 \%$ or at least $0.3 \mu \mathrm{mol} \mathrm{mol}^{-1}$ for the water vapour mixing ratio, yielding an overall uncertainty of $\approx 10 \%$ for the conditions of this study. The water vapour mixing ratios measured by the CR2 were generally in good agreement with the measurements by FISH during the CONCERT contrail flights (Gayet et al., 2012).

\subsection{The NO and $\mathrm{NO}_{\mathrm{y}}$ chemiluminescence instrument}

Aircraft exhaust plumes can be identified using in situ measurements by enhancements in $\mathrm{NO}$ and $\mathrm{NO}_{\mathrm{y}}$ mixing ratios (Schulte et al., 1997). NO and $\mathrm{NO}_{\mathrm{y}}$ are measured with the chemiluminescence technique using two separate rear-facing inlets. In the rear-facing inlets, particles larger than $0.5 \mu \mathrm{m}$ are stripped from the sampling air due to inertia, and predominantly gas phase $\mathrm{NO}_{\mathrm{y}}$ is measured (Meilinger et al., 1999). $\mathrm{NO}_{\mathrm{y}}$ is catalytically reduced to $\mathrm{NO}$ in a gold converter heated to $30{ }^{\circ} \mathrm{C}$ using $\mathrm{CO}$ as reducing agent. Finally, the chemiluminescence reaction of $\mathrm{NO}$ with $\mathrm{O}_{3}$ is detected. The $\mathrm{NO}_{\mathrm{y}}$ instrument has an accuracy of $\pm 10 \%$ for $\mathrm{NO}$ and $\pm 12 \%$ for $\mathrm{NO}_{\mathrm{y}}$ (Voigt et al., 2008). With the $\mathrm{NO}_{\mathrm{y}}$ instrument, the uptake of $\mathrm{HNO}_{3}$ in contrail ice crystals has also been investigated (Schäuble et al., 2009).

\section{Contrail chasing and meteorology}

The meteorological situation over Germany on 19 November 2008 was influenced by a high pressure system located over the Atlantic northwest of France and a low pressure system over northern Scandinavia. Cold and humid air with cirrus clouds was advected over Germany in a northern flow and expanded towards the east during the day. The contrails were probed at altitudes near or above the cirrus top.

Three contrails from the A319, A340 and A380 aircraft were visually observed during the flight (Fig. 1), all at flight level 350 hectofeet (10668 $\mathrm{m}$ pressure altitude). The temperature at this flight level was about $6 \mathrm{~K}$ below the Schmid-Appleman threshold temperature for contrail formation; see Table 1 (Schumann, 1996). The Falcon pilots descended/ascended into the contrails for in situ measurements and profiled the contrails at different positions with respect to the contrail axis. In the data sets (Fig. 2), contrails were identified by a simultaneous increase in the NO mixing ratio $\left(\mathrm{NO}>0.15 \mathrm{nmol} \mathrm{mol}^{-1}\right.$ ) and the particle number concentration $\left(>0 \mathrm{~cm}^{-3}\right.$ for $\left.D>2.8 \mu \mathrm{m}\right)$. To investigate the impact of the aircraft type on contrail properties, we selected observations performed under similar ambient conditions (see Table 1) and at similar contrail ages (80-118 s). The corresponding age was calculated from the difference between the position of the contrail-producing aircraft and the Falcon, taking measured wind speeds into account (Jurkat et al., 2011). In the contrail sequences, mean RHI of $91 \%$ (A319), $94 \%$ (A340) and $92 \%$ (A380) were identified from the measurements. For the A319, the RHI measured in ambient air was $94 \%$, slightly higher than inside the contrail. Similar RHI (94\%) has been measured inside and near/above the A340 and the A380 contrails, and slightly lower values below the contrails (see discussion by Gayet et al., 2012). For $0.5 \mathrm{~K}$ lower temperatures, which are within the measurement uncertainty of the temperature measurements of the Falcon, the RHI may actually be close to ice saturation ( $98 \%$ to $101 \%$ ) and still within the range of instrumental uncertainties of $\pm 10 \%$ in RHI.

Table 1 summarizes meteorological conditions and aircraft properties in three contrail sequences, which were selected according to similar contrail age and RHI. In addition, the fuel flow, engine type, Mach number, aircraft registration and weight were reported by the pilots (with unknown accuracy). The $\mathrm{NO}_{\mathrm{x}}$ emission index $\left(\mathrm{EI}_{\mathrm{NO}_{\mathrm{x}}}\right)$ was determined as in Döpelheuer and Lecht (1999), based on aircraft and engine type and the fuel flow. For the A380 aircraft, the reported fuel flow of $4.75 \mathrm{t}$ (h engine $)^{-1}$ was reduced by $30 \%$ to match expected fuel flow records (Jurkat et al., 2011).

\section{Particle properties in the A319, A340 and A380 contrails}

\subsection{Mean particle size and surface area distributions}

Particle size and surface area distribution of 80 to 118 s-old contrails from the A319, A340 and A380 aircraft are shown in Fig. 3. Ambient cirrus ice crystals did not significantly disturb the particle size distributions of the young contrails (Fig. 3a, grey line). Vortex dynamics and wind shear lead to strong variations in the particle concentrations in contrails (e.g. Sussmann and Gierens, 2001). To obtain a representative particle size distribution, it is necessary to perform measurements at various positions in the contrail. As the contrail is heterogeneous on a small scale, we assume that after more 
Table 1. Conditions for a subset of observations selected to investigate the impact of the aircraft type on contrail properties. Encounter time and contrail altitude are given for the complete contrail encounters; the other values correspond to the selected contrail sequences. The latitude and longitude are given for the central time of observation. Pressure, temperature, reactive nitrogen $\left(\mathrm{NO}_{\mathrm{y}}\right)$ mixing ratio and relative humidity with respect to ice (RHI) have been measured on board the Falcon. The threshold temperature for contrail formation is calculated for an overall propulsion efficiency of 0.3 and the given RHI. The fuel flow rate $\left(m_{\mathrm{F}}\right)$ was reported by the pilots of the commercial aircraft. The contrail age and $\mathrm{NO}_{\mathrm{x}}$ emission index $\left(\mathrm{NO}_{\mathrm{x}}=\mathrm{NO}+\mathrm{NO}_{2}\right)$ have been calculated as detailed in the text. The fuel sulphur content has been measured for the A319 and A340 aircraft.

\begin{tabular}{|c|c|c|c|}
\hline Aircraft & A319-111 & A340-311 & A380-841 \\
\hline Encounter time & $09: 14-09: 27$ & $08: 45-08: 48$ & $12: 14-12: 29$ \\
\hline Contrail altitude (km) & $10.5-10.7$ & $10.5-10.7$ & $10.3-10.7$ \\
\hline Latitude & $52.91^{\circ} \mathrm{N}$ & $53.35^{\circ} \mathrm{N}$ & $52.37^{\circ} \mathrm{N}$ \\
\hline Longitude & $8.06^{\circ} \mathrm{E}$ & $8.94^{\circ} \mathrm{E}$ & $9.66^{\circ} \mathrm{E}$ \\
\hline Pressure $p(\mathrm{hPa})$ & 241 & 242 & 241 \\
\hline Temperature $T(\mathrm{~K})$ & 217 & 217 & 218 \\
\hline$T_{\mathrm{C}}(\mathrm{K})$ & 223.5 & 223.6 & 223.6 \\
\hline Brunt-Väisälä frequency & 0.0170 & 0.0126 & 0.0132 \\
\hline $\mathrm{NO}_{\mathrm{y}}\left(\mathrm{nmol} \mathrm{mol}{ }^{-1}\right)$ & 4.3 & 4.4 & 6.7 \\
\hline $\mathrm{EI}_{\mathrm{NO}_{\mathrm{x}}}\left(\mathrm{g} \mathrm{kg}^{-1}\right)$ & 8.7 & 11.6 & 19.7 \\
\hline RHI $(\%)$ & 91 & 94 & 92 \\
\hline Contrail age (s) & $105-118$ & $80-90$ & $102-115$ \\
\hline Fuel flow (Mg engine ${ }^{-1} \mathrm{~h}^{-1}$ ) & 0.9 & 1.3 & 3.6 \\
\hline Fuel flow rate $\left(\mathrm{kg} \mathrm{km}^{-1}\right)$ & 2.2 & 6.4 & 15.9 \\
\hline Aircraft engine & CFM56-5B6/P & CFM56-5C2 & Trent $970-84$ \\
\hline Mach & 0.76 & 0.737 & 0.85 \\
\hline Fuel sulphur content $\left(\mathrm{mg} \mathrm{kg}^{-1}\right)$ & 1155 & 940 & - \\
\hline Aircraft weight (Mg) & 47 & 150 & 508 \\
\hline Wingspan (m) & 34.09 & 60.30 & 79.81 \\
\hline
\end{tabular}

than $60 \mathrm{~s}$ (12000 m flight path) of contrail probing, our averaged particle size distribution is representative of the mean state inside the contrail. In the following, we first list the contrail properties derived from observations for the A319, followed by the A340 and the A380. The aircraft weights and wing span sizes, as listed in Table 1, differ significantly between the three aircraft.

We calculate the optical effective diameter of the contrail ice particles with

$D_{\text {eff }}=(3 / 2)(V / A)$

with the total ice particle volume $\mathrm{V}$ and the total projected particle cross-sectional area $\mathrm{A}$. The particle size distributions of the three contrails from the A319, A340 and A380 aircraft have similar effective diameters $D_{\text {eff }}$ of $5.2 \mu \mathrm{m}, 5.8 \mu \mathrm{m}$ and $5.9 \mu \mathrm{m}$, which are equal within the instrumental uncertainties. Yet the observed particle number density $n_{\text {ice }}$ $(D>0.93 \mu \mathrm{m})$ increases with increasing aircraft weight from $162 \mathrm{~cm}^{-3}$ to $235 \mathrm{~cm}^{-3}$ (Table 2).

The projected planar ice crystal surface area $A_{\mathrm{p}}$ of the contrail size distribution (Fig. 3b) also increases for heavier aircraft from $0.93 \times 10^{3}$ to $1.45 \times 10^{3} \mu \mathrm{m}^{2} \mathrm{~cm}^{-3}$ in our case. It is dominated by particles in the diameter range $2.8 \mu \mathrm{m}$ to $12.9 \mu \mathrm{m}$. This size range accounts for $\approx 95 \%$ of the total ice particle surface area in the three contrails.
The vertical profile of the A380 contrail probed at a mean contrail age of $122 \mathrm{~s}$ is shown for reference in Fig. 4. NO and ice particle number densities are enhanced over the vertical contrail depth of at least $270 \mathrm{~m}$. At least the upper part of the primary vortex has been probed, indicated by high NO mixing ratios and high particle concentrations. Strong turbulence made the pilots ascend soon into the secondary wake during this observation sequence. Interestingly, the particle number concentrations are enhanced also in the secondary wake, in the same order of magnitude as in the primary wake.

\subsection{Contrail optical depth distributions}

The optical and microphysical properties are calculated according to Schumann et al. (2011). We calculate the extinction coefficient using

$\beta=\int Q_{\text {ext }}(D) A_{\mathrm{p}}(D) n_{\mathrm{p}}(D) \mathrm{d} D$,

with the extinction efficiency $Q_{\text {ext }}$, the mean projected particle cross-sectional area $A_{\mathrm{p}}$, the number of ice particles $n_{\mathrm{p}}$, and the diameter $D$. The integral is computed by a discrete summation over all grouped channels of the FSSP300. The extinction efficiency $Q_{\text {ext }}$ has been calculated for each size bin using Mie theory for an optical wavelength of $550 \mathrm{~nm}$. $Q_{\text {ext }}$ shows the well-known Mie oscillations for 

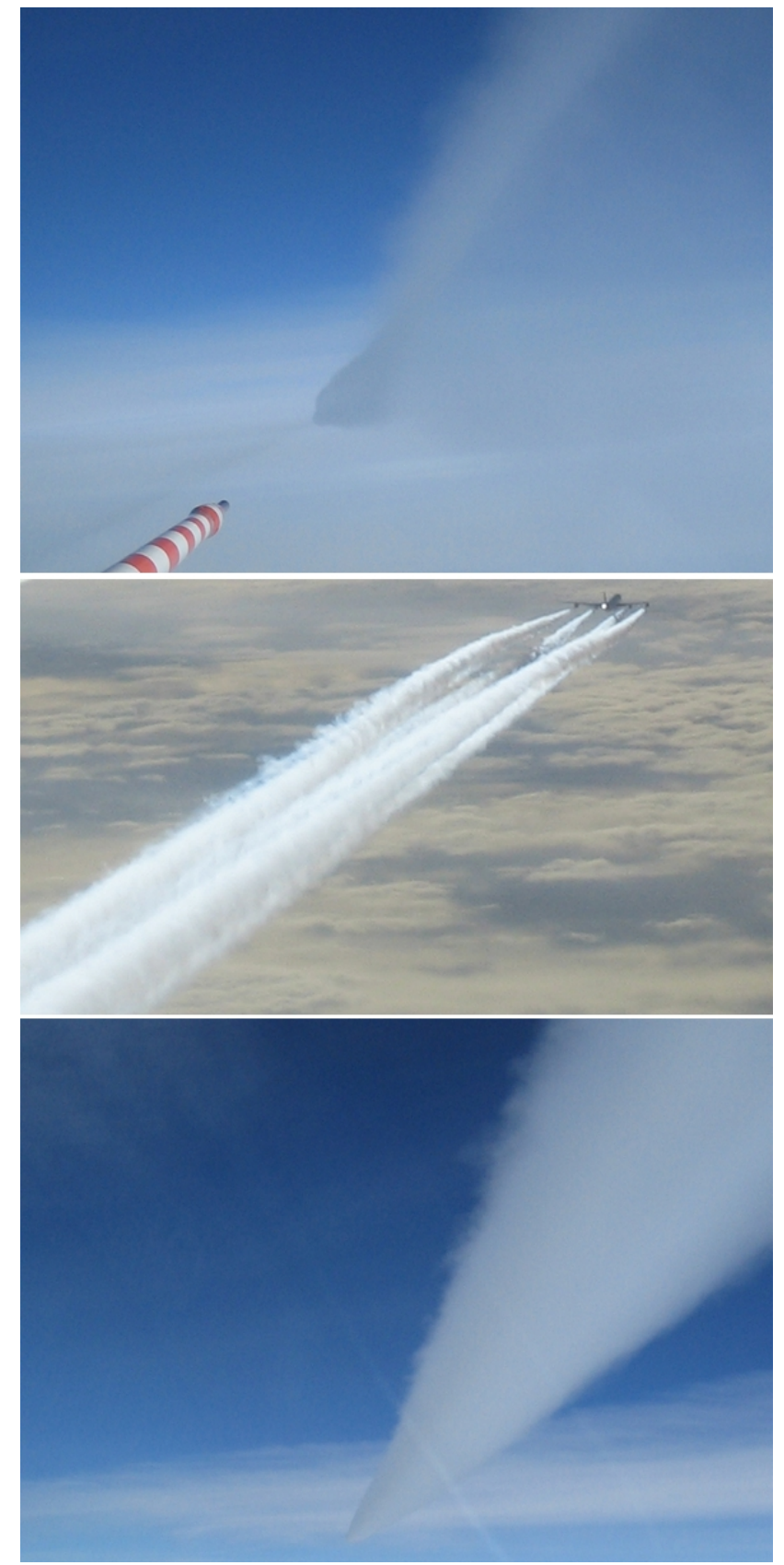

Fig. 1. Probing contrails from three aircraft (top: A319, middle: A340 and bottom: A380) on 19 November 2008 above Germany. The photos are taken from the cockpit of DLR research aircraft Falcon. The nose boom of the Falcon is visible in the top photo.

particle diameters of the order of the wavelength, and approaches 2 for larger particles.

The distributions of extinction and optical depth $\tau$ at $550 \mathrm{~nm}$ are calculated from the high frequency $(1 \mathrm{~s})$ particle size distribution measurements and the estimated vertical depths of the contrails. The normalized probability density function of contrail extinction is shown in Fig. 5a.
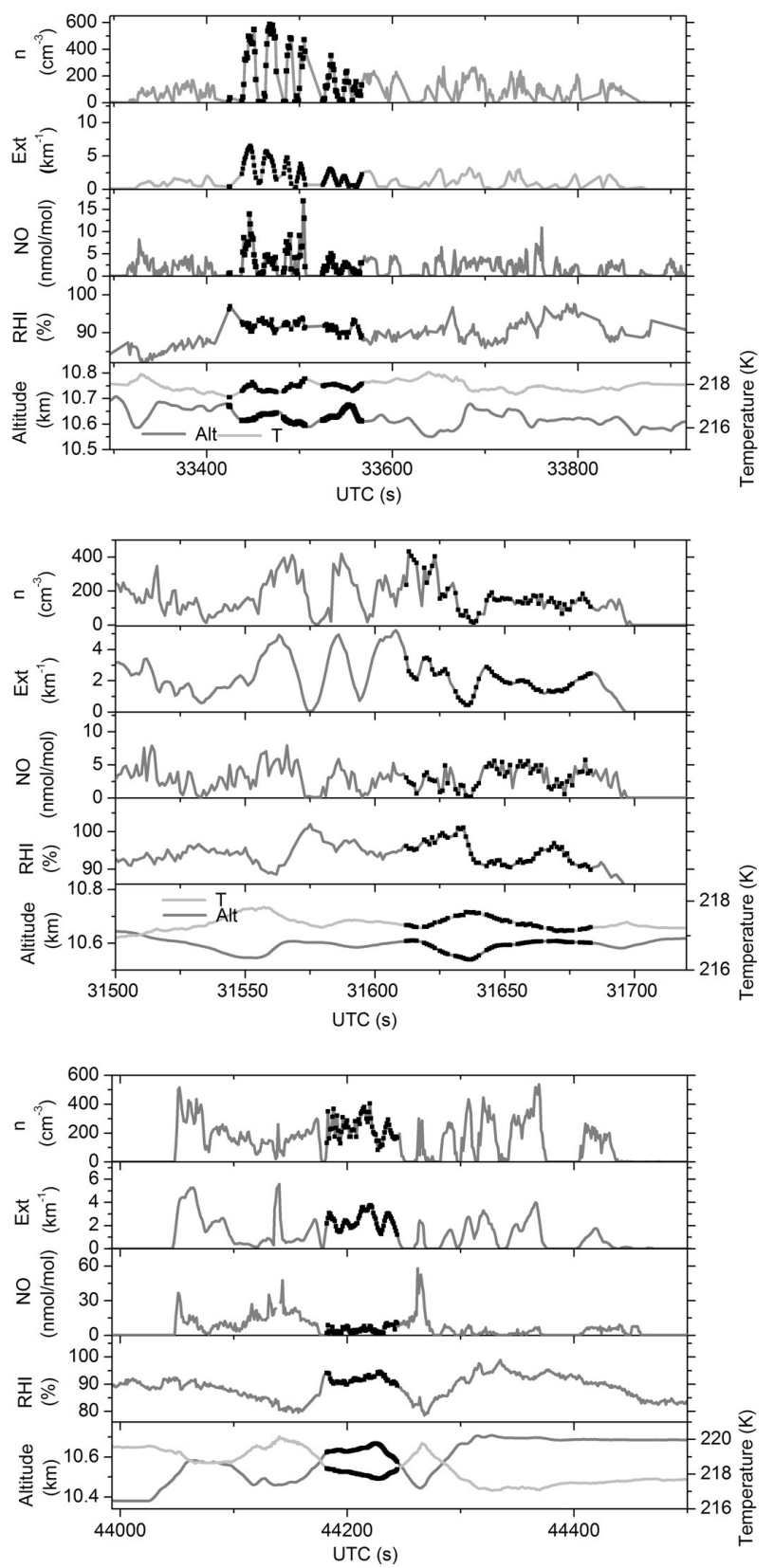

Fig. 2. Time series of contrail observations of the A319 (top), A340 (middle) and A380 (bottom) aircraft as described in Fig. 1. Particle number density $n$ (for diameters $D>2 \mu \mathrm{m}$ ), extinction $\beta$, RHI, temperature $T$ and flight altitude are shown. Contrail sequences used to investigate the aircraft influence on contrail properties are marked with black squares.

An overview of the mean macrophysical, microphysical and optical contrail properties is given in Table 2. Mean extinctions increase from 2.1 to $3.2 \mathrm{~km}^{-1}$ with aircraft weight. The vertical depth of the contrails is deduced based on calculations with the P2P model (Holzäpfel, 2003) for atmospheric conditions prevailing during the flights. The P2P 
Table 2. Microphysical, macrophysical and optical properties of the selected contrail sequences from A319, A340 and A380 aircraft, derived from FSSP-300 measurements. Mean particle number density $(D>0.93 \mu \mathrm{m})$, effective diameter $D_{\text {eff }}$, projected planar surface area $A_{\mathrm{p}}$, ice water content IWC, vertical extension and optical depth $\tau$ are given for the three aircraft.

\begin{tabular}{llllllll}
\hline Aircraft & $\begin{array}{l}n_{\text {ice }} \\
\left(\mathrm{cm}^{-3}\right)\end{array}$ & $\begin{array}{l}D_{\text {eff }} \\
(\mu \mathrm{m})\end{array}$ & $\begin{array}{l}\text { Projected surface } \\
\text { area } A\left(\mu \mathrm{m}^{2} \mathrm{~cm}^{-3}\right)\end{array}$ & $\begin{array}{l}\text { IWC } \\
\left(\mathrm{mg} \mathrm{m}^{-3}\right)\end{array}$ & $\begin{array}{l}\text { Extinction } \\
\left(\mathrm{km}^{-1}\right)\end{array}$ & $\begin{array}{l}\text { Vertical } \\
\text { extension }(\mathrm{m})\end{array}$ & $\begin{array}{l}\text { Optical } \\
\text { depth } \tau\end{array}$ \\
\hline A319 & $162 \pm 18$ & $5.2( \pm 1.5)$ & $0.93( \pm 0.14) \times 10^{3}$ & $4.1( \pm 1.0)$ & $2.1( \pm 0.3)$ & 120 & 0.25 \\
A340 & $164 \pm 0.11$ & $5.8( \pm 1.7)$ & $1.12( \pm 0.17) \times 10^{3}$ & $4.0( \pm 1.0)$ & $2.5( \pm 0.4)$ & 220 & 0.55 \\
A380 & $235 \pm 10$ & $5.9( \pm 1.7)$ & $1.45( \pm 0.22) \times 10^{3}$ & $5.2( \pm 1.3)$ & $3.2( \pm 0.5)$ & 290 & 0.94 \\
\hline
\end{tabular}

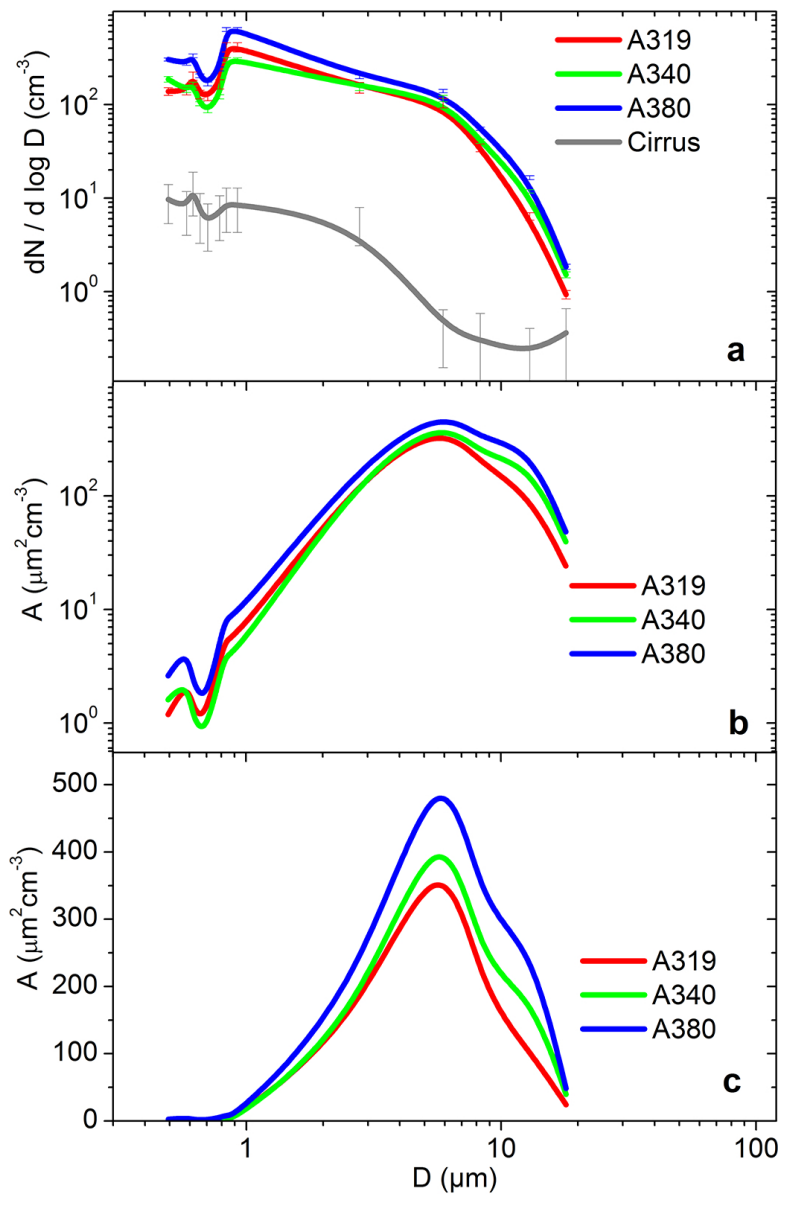

Fig. 3. Particle size distribution (a) and projected planar surface area distribution in logarithmic scale (b) and linear scale (c) of the selected contrail sequences from A319, A340 and A380 aircraft versus particle diameter $D$. Higher total particle concentrations are observed in the contrails from heavier aircraft (A380: $580 \mathrm{Mg}, \mathrm{A} 340$ : $150 \mathrm{Mg}, \mathrm{A} 319: 47 \mathrm{Mg}$ ), also leading to higher surface area distributions. The maximum in the surface distribution at a diameter near $7 \mu \mathrm{m}$ dominates the optical properties of the contrails. The error bars correspond to errors in counting statistics and are small due to large particle numbers. In panel (a) the particle size distribution of a surrounding cirrus cloud is also shown for reference. Obviously, effects by ambient cirrus clouds on the microphysical contrail properties are negligible.

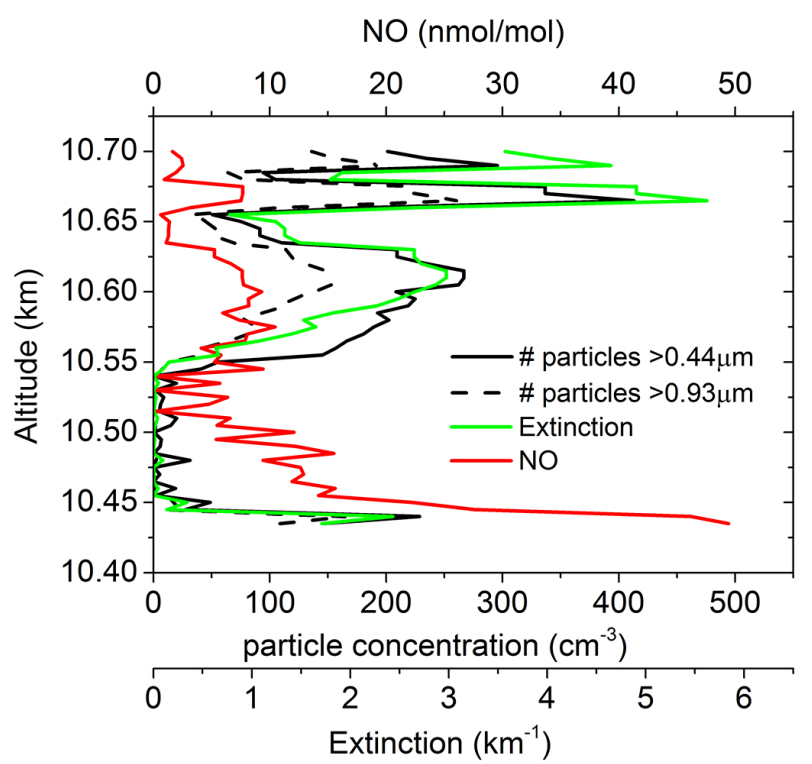

Fig. 4. Profile of the ice particle concentrations for $D>0.44$ and $D>0.93 \mu \mathrm{m}$, extinction derived from FSSP data and NO levels in the A380 aircraft case versus altitude. The profile has been recorded in the time between $44223 \mathrm{~s}$ and $44327 \mathrm{~s}$ UTC (see Fig. 2, bottom panel) at a mean contrail age of $108 \mathrm{~s}$. Enhanced particle concentrations and NO mixing ratios are observed over a vertical range of $270 \mathrm{~m}$. The primary vortex has been entered at altitudes below $10.45 \mathrm{~km}$. It may extend further down.

model calculates the sinking distance of the primary vortices. We assume that the contrail develops between the flight altitude of the contrail-producing aircraft and the primary vortices structure. The sinking distances of the vortices and the detrainment of ice particles out of the vortices control the vertical contrail depth. The depth values depend on the weight, speed and wing span of the individual aircraft and, in addition, on the meteorological situation, in particular the thermal stratification (Holzäpfel, 2006). The calculated contrail depths are in agreement $( \pm 20 \%)$ with contrail dimensions derived from the maximum vertical distance between the contrail-producing aircraft and the Falcon during contrail observations. 


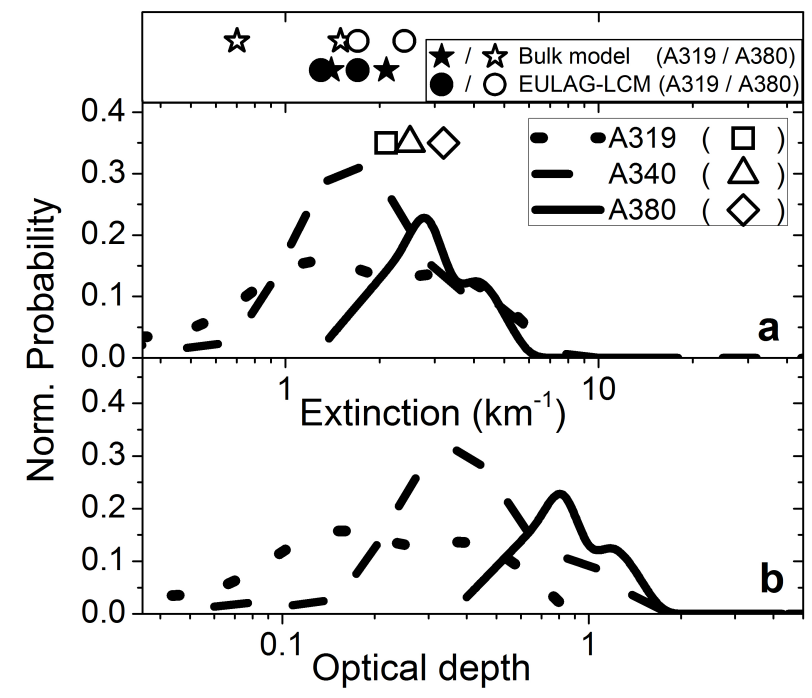

Fig. 5. Normalized frequency distributions of extinction (a) and optical depth (b) of the selected sequences from the A319, A340 and A380 contrails. Mean extinction values of the three aircraft are shown in (a) by empty symbols. Mean and maximum extinction and optical depth increase with increasing aircraft weight under similar meteorological conditions. For comparison, the mean extinction values derived by EULAG-LCM and the bulk model are shown in the upper panel for the two airliners for $97 \%$ (103\%) ambient RHI, with the lower values for $97 \%$ ambient RHI.

The optical depth is derived from the product of the extinction coefficients and the depth of the wake. We find contrail optical depths of $0.25,0.55$ and 0.94 for the A319, A340 and A380 aircraft (Table 2), suggesting that heavier aircraft produce optically thicker contrails under similar meteorological conditions. The assumption that the mean extinction coefficient is representative of the whole depth of wake may lead to upper bounds. The contrail optical depth distribution is shown in Fig. 5b. The slight dip in the frequency distribution of the contrail optical depth of the A380 aircraft could be an effect of low sampling statistics in the contrail optical depth range near 1 . The larger vertical thickness of contrails of heavier aircraft caused by the stronger descent of the vortices contributes significantly to the increase in contrail optical depth. In addition, enhanced particle number densities also yield higher particle surface areas for larger aircraft.

We also calculate the fraction of the contrail ice water content IWC, which originated from the engine exhaust itself. Assuming $\mathrm{NO}_{\mathrm{y}}$ as an inert tracer in the 2 min time scale from engine exit to contrail encounter, the dilution of the engine emissions in the young contrails can be calculated using $\mathrm{EI}_{\mathrm{NO}_{\mathrm{x}}}$ and the mean observed $\mathrm{NO}_{\mathrm{y}}$ values. If water and later ice were similarly diluted, and assuming that all of the water emitted by the aircraft had been taken up by contrail ice particles, we calculate the fraction of aircraft water emissions to the observed ice water contents in the contrails. We find that less than $10 \%$ of the contrail ice particle mass originates from the aircraft exhaust water in the 2 min-old contrails, suggesting that ice supersaturation prevailed during contrail growth.

\section{Model simulations and results}

The evolution of contrails in the vortex phase is influenced both by aircraft parameters and the atmosphere. Allowing identical meteorological conditions, in contrast to observations, model simulations may be used to study contrail evolution influenced only by different aircraft types. We perform numerical simulations of the evolution of contrail properties in the vortex phase with two independent models, the EULAG-LCM model system (Sölch and Kärcher, 2010) and the CoCiP model (Schumann, 2012). This way we can separate the aircraft effect from atmospheric variability and gain a better insight into and understanding of the observed results. Moreover, we will test the sensitivity of contrail RF to the properties of young contrails.

\subsection{Cloud-resolving model study}

\subsubsection{The EULAG-LCM model system}

The EULAG-LCM model (Sölch and Kärcher, 2010) is a large-eddy model based on the inelastic numerical solver for EULAG geophysical flows (Grabowski and Smolarkiewicz, 2002). The model was originally designed to study the formation and evolution of natural cirrus clouds, and was recently used to study the evolution of contrails in the vortex phase (Unterstrasser and Sölch, 2010). A combined Eulerian/Lagrangian approach is used to simulate the evolution of the contrail ice crystals and their interaction with the wake dynamics with the help of the LCM microphysical module. Water vapour and trace gases are treated similarly to the dynamical and thermodynamical variables in a fixed Eulerian grid. In contrast, the ice phase is treated by tracking a large number of simulation ice particles (SIP) in the flow field. Each SIP represents a number of real ice crystals with identical properties. We calculate the depositional growth or sublimation of ice crystals by interaction with water vapour, their gravitational sedimentation, and turbulent dispersion on ice crystal trajectories. Ice formation, aggregation, and radiative processes are excluded in the model runs, as these are of minor importance for contrail physics in the vortex phase. Effects of buoyancy of the exhaust plume due to a higher initial temperature in the exhaust plume are not considered directly, but the effects are represented by additional small scale turbulence added to the aircraft wake.

\subsubsection{Atmospheric conditions and contrail initialization}

For analysis of the influence of the aircraft type on the contrail evolution and resulting optical depth, the evolution of the contrails of the A319 and A380 are simulated 
Table 3. Initialization and settings of the EULAG-LCM model for the contrail simulations.

\begin{tabular}{|c|c|c|}
\hline Domain & A319 & A380 \\
\hline Grid cells & $256 \times 400 \times 256$ & $256 \times 400 \times 512$ \\
\hline Grid spacing & \multicolumn{2}{|c|}{$\Delta x=\Delta y=\Delta z=1 \mathrm{~m}$} \\
\hline Time steps & $\Delta t=0.04 \mathrm{~s}$ & $\Delta t=0.02 \mathrm{~s}$ \\
\hline Total time & \multicolumn{2}{|c|}{$120 \mathrm{~s}$} \\
\hline \multicolumn{3}{|l|}{ Atmosphere } \\
\hline $\begin{array}{l}\text { Stability } \\
\text { Eddy dissipation rate } \\
\text { Ice saturation ratio }\end{array}$ & \multicolumn{2}{|c|}{$\begin{array}{c}\mathrm{N}^{2}=1.44 \times 10^{-4} \mathrm{~s}^{-2} \\
\varepsilon=6.25 \times 10^{-5} \mathrm{~s}^{-3} \\
S_{i}=0.97\end{array}$} \\
\hline \multicolumn{3}{|l|}{ Wake properties } \\
\hline $\begin{array}{l}\text { Initial circulation } \\
\text { Number of ice particles per flight distance } \\
\text { Jet radius } \\
\text { SIP }\end{array}$ & $\begin{array}{c}\Gamma_{0}=197.61 \mathrm{~m}^{2} \mathrm{~s}^{-2} \\
\mathrm{~N} 0=0.072 \times 10^{13} \mathrm{~m}^{-1} \\
r_{0}=12 \mathrm{~m} \\
70 \times 10^{6}\end{array}$ & $\begin{array}{c}\Gamma_{0}=652.9 \mathrm{~m}^{2} \mathrm{~s}^{-2} \\
\mathrm{~N} 0=0.378 \times 10^{13} \mathrm{~m}^{-1} \\
r_{0}=22 \mathrm{~m} \\
236 \times 10^{6}\end{array}$ \\
\hline
\end{tabular}

in a three-dimensional domain, with horizontal extensions of $256 \mathrm{~m} \times 400 \mathrm{~m}$ and $256 \mathrm{~m}$ and $512 \mathrm{~m}$ in vertical extent, with $1 \mathrm{~m}$ resolution, initialized as given in Table 3 . Atmospheric profiles of temperature and pressure are specified on the base of the observation. As the profile of RHI at the time of contrail formation is not known precisely, we assume a constant profile over height at model initialization. Any horizontal variability in flight direction is not resolved in the small LES domain. The model atmosphere is stably stratified with $N=0.012 \mathrm{~s}^{-1}$, similar to observational values. We superimpose a grid scale ambient turbulence field (mean eddy dissipation rate of $\varepsilon=6.25 \times 10^{-5} \mathrm{~m}^{2} \mathrm{~s}^{-3}$ ) onto the model domain, generated with a separate LES simulation to match the reported turbulence level. At initialization we assume that the vortex roll-up process is fully completed and impose two counter-rotating vortices with a Lamb-Oseen profile of tangential velocity and an initial circulation according to Table 3 . The initial circulation strength $\Gamma_{0}$ is calculated from the reported mass, airspeed and wingspan of the aircraft at the time of the measurements. We start the simulation at a contrail age of $20 \mathrm{~s}$ and introduce the contrail's ice crystals inside two circles around the vortex cores with jet area radii $r_{0}$ (see Table 3 ), with a spatially uniform crystal distribution. Different geometrical assumptions of the initial distribution may alter resulting ice crystal concentrations up to $10 \%$. The number of ice crystals per metre of flight path $N_{0}$ is estimated with assumed soot emission indices. $\mathrm{EI}_{\text {soot }}=0.323 \times 10^{15} \mathrm{~kg}^{-1}$ and $E I_{\text {soot }}=0.236 \times 10^{15} \mathrm{~kg}^{-1}$ are chosen for the A319 and A380, respectively, being representative estimates for regional and large aircraft (Eyers et al., 2004, their Table 31), based on engine calculations of Döpelheuer (2002). The values are in good general agreement with the few measurements of soot emission of cruising airliners with different engines $\left(1.8-6 \times 10^{14}\right)$ (Anderson et al., 1998; Petzold et al., 1999; Schumann et al., 2002) and with the decrease of soot number emission indices for more modern engines (Petzold et al., 2005). However, the previous soot emission measurements were taken behind aircraft with low power settings. Recent studies suggest a significant increase in the emission index of black carbon mass for higher fuel flows (Stettler et al., 2013). New evidence based on our observations shows that the soot emissions may have been underestimated and at least as high as $1.0 \times 10^{15} \mathrm{~kg}^{-1}$ (Schumann et al., 2013), leading to further uncertainties in the initial ice crystal number. For higher initial ice crystal numbers, more particles with a smaller mean radius would form, as the total IWC would remain the same due to unchanged $\mathrm{EI}_{\mathrm{H}_{2} \mathrm{O}}$ and atmospheric supersaturation. This would lead to initially larger extinction and optical depth values due to larger particle surfaces. However, with contrail aging, more particles would sublimate, especially in the primary vortex, so for higher contrail age the extinctions may be reduced. The absolute effect of larger initial ice crystal numbers also depends on the atmospheric background conditions.

It is assumed that each emitted soot particle forms an ice crystal, which should be reasonable for low fuel sulphur content (Schumann et al., 2002). Hence, the initial ice crystal numbers depend on engine type and fuel flow. Finally, we assume that the initial ice crystals contain exactly the amount of water vapour emitted from the engines. In each grid box the ice crystal size distribution is supposed to be lognormal (Unterstrasser and Sölch, 2010). Overall, we track more than $70 \times 10^{6}\left(236 \times 10^{6}\right) \mathrm{SIP}$, each representing on average $10300(16000)$ ice particles for the A319(A380) case, respectively. 
Table 4. Parameters used in the EULAG-LCM model (top) and model results (bottom). Extinction, optical depth $\tau$, effective diameter $D_{\text {eff }}$, particle number density $n_{\text {ice }}$ and the ice crystal survival factor are calculated with the EULAG-LCM model simulating the observation process. Results for assumed initial RHI of $97 \%$ and $103 \%$ are shown. $\mathrm{NO}_{\mathrm{y}}$ values are calculated under the assumption of $\mathrm{NO}_{\mathrm{y}}$ being a passive, non-reactive tracer. Initial $\mathrm{NO}_{\mathrm{y}}$ values are calculated by using $\mathrm{EI}_{\mathrm{NO}_{\mathrm{x}}}$ (Table 1) and assuming that all $\mathrm{NO}_{\mathrm{y}}$ is trapped within the vortex at $20 \mathrm{~s}$ contrail age.

\begin{tabular}{|c|c|c|c|c|c|}
\hline & unit & A319 & A319 & A380 & A 380 \\
\hline RHI & $\%$ & 97 & 103 & 97 & 103 \\
\hline Pressure $p$ & mbar & 241 & 241 & 241 & 241 \\
\hline Temperature $T$ & $\mathrm{~K}$ & 217 & 217 & 217 & 217 \\
\hline Contrail age & $\mathrm{s}$ & 100 & 100 & 100 & 100 \\
\hline $\mathrm{EI}_{\text {soot }}$ & $10^{14} \mathrm{~kg}^{-1}$ & 3.23 & 3.23 & 2.36 & 2.36 \\
\hline $\mathrm{NO}_{\mathrm{y}}$ mixing ratio & $\mathrm{nmol} \mathrm{mol}^{-1}$ & 11.4 & 11.4 & 20 & 20 \\
\hline Ice water content IWC & $\mathrm{mg} \mathrm{m}^{-3}$ & 1.1 & 1.6 & 1.4 & 1.9 \\
\hline Ice particle concentration $n_{\text {ice }}$ & $\mathrm{cm}^{-3}$ & 92 & 217 & 166 & 372 \\
\hline Effective diameter $D_{\text {eff }}$ & $\mu \mathrm{m}$ & 3.8 & 3.6 & 3.4 & 3.3 \\
\hline Net vertical extension $H$ & $\mathrm{~m}$ & - & 54.1 & - & 60.1 \\
\hline Net horizontal extension $B$ & $\mathrm{~m}$ & - & 36.9 & - & 86.7 \\
\hline Optical depth $\tau$ & & - & 0.09 & - & 0.16 \\
\hline Mean extinction $\beta$ & $\mathrm{km}^{-1}$ & 1.3 & 1.7 & 1.7 & 2.4 \\
\hline Survival factor at $100 \mathrm{~s}$ & & - & 0.72 & - & 0.69 \\
\hline
\end{tabular}

\subsubsection{Calculation of the evolution of the A319 and A380 contrails under identical meteorological conditions}

We model the evolution of the contrails of an A319 and an A380 aircraft with the EULAG-LCM model (Sölch and Kärcher, 2010) with atmospheric parameters shown in Table 4. As discussed above, the observed contrails must have experienced local ice supersaturation in the first minutes of their lifetimes in order to explain the high ice water content in the observations. In addition, a growth of ice particles has been observed in the A380 contrail (Gayet et al., 2012). This indicates that ambient air was close to saturation or even supersaturated. Hence, background relative humidity was set to $97 \%$ and $103 \%$ in different model runs, respectively, which is at the upper limit of observations but still within the instrumental uncertainties. For the case of RHI $=103 \%$, further model evaluation to assess both horizontal and vertical extension of the contrail and the fraction of the surviving ice crystals has been performed for the A319 and A380. The derived net horizontal and net vertical extensions are calculated considering only grid cells containing ice particles and thus are usually smaller than the potential maximum extensions.

A special procedure is used to compute particle size distributions averaged along the plume for comparison with observations. The exact measurement position relative to the vortex centres is unknown, since the contrail was deformed by local wind and turbulence. Therefore, the model results were averaged along simulated linear flight paths. Linear flight paths were randomly chosen as horizontal lines through the model grid with a randomly chosen starting point. Virtual flight paths that did not include any simulated ice particles were excluded from the analysis, similar to the criteria applied to the observational data. A total of 16300 (19700) simulated particle size distributions was recorded for the A319 (A380) aircraft, respectively.

The mean particle size distributions and planarprojected surface distributions obtained for A319/A380 for $\mathrm{RHI}=97 \%$ with respect to ice are shown in Fig. 6a and $\mathrm{b}$ and particle number concentrations for particles $>0.5 \mu \mathrm{m}$ and effective diameter are given in Table 4 . In addition, the measured particle size distribution in the A319 contrail is shown for comparison. Both observations and model results show an increase in ice number density for heavier aircraft and similar particle size distributions for both aircraft. However, the modelled ice size distributions have slightly lower effective diameters compared with the observations. For large particles $(D>10 \mu \mathrm{m})$, the simulated particle number densities deviate significantly from observations. This deviation cannot be explained using higher RHI in the simulation, as particle losses in the young contrail are reduced so that the total particle number density at the time of measurements is enhanced at higher RHI (see Fig. 7).

In addition, we investigate the impact of RHI on the ice crystal size distribution in contrails. An increase in the atmospheric background relative humidity to $103 \%$ has a strong impact on contrail parameters such as ice number density $n_{\text {ice }}$ and contrail optical depth (Table 4) in the simulation results. $n_{\text {ice }}$ is reduced in subsaturated conditions due to sublimation of particles at the lower end of the size distribution. Effective diameters are nearly unchanged and vary by $<10 \%$ for $97 / 103 \%$ RHI. At higher ice supersaturation, $D_{\text {eff }}$ increases due to enhanced water uptake by the ice particles. 


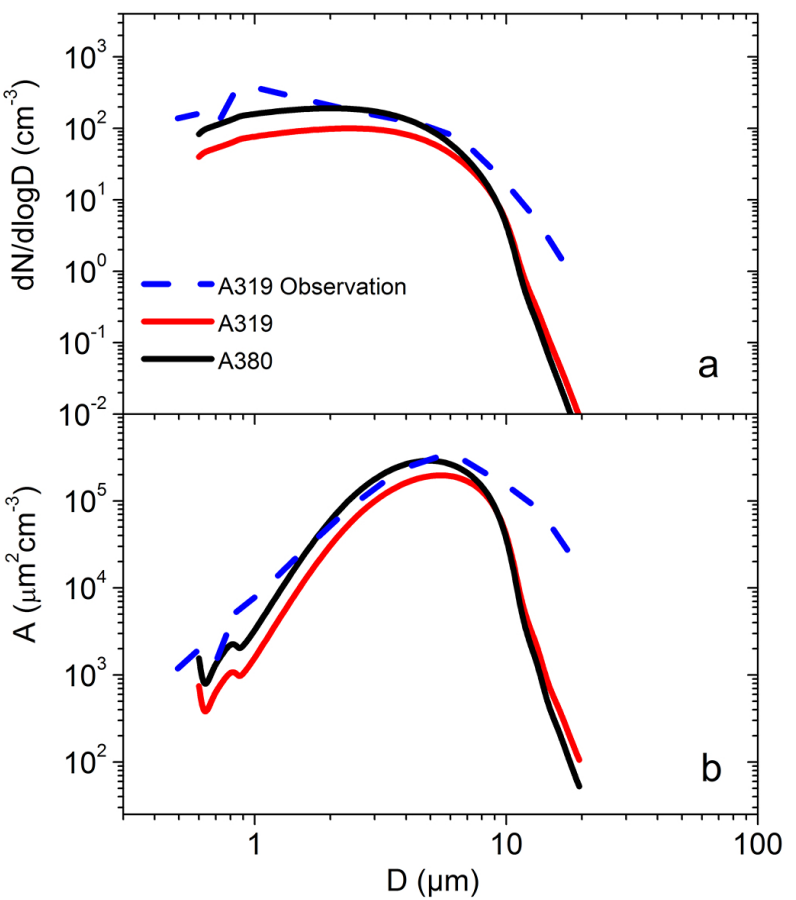

Fig. 6. Average particle size and planar-projected surface area distributions from A319 (red) and A380 (black) aircraft contrails calculated with the EULAG-LCM model for ambient RHI $97 \%$. The dashed blue line corresponds to the observed particle size and surface distribution. The particle size distributions have a similar shape in model and observation for $D<10 \mu \mathrm{m}$, with significant differences for $D>10 \mu \mathrm{m}$ and higher total number concentrations in the observation. The optical properties of the contrails are dominated by particles with $D \approx 6 \mu \mathrm{m}$.

A large discrepancy between the observation and the modelling of a contrail by an A380 aircraft has been found regarding the evolution of a secondary wake. While during observation, large numbers of ice particles are found in the secondary wake (see Fig. 4), no significant number of ice particles is apparent in the model at A380 flight altitude at $t=100 \mathrm{~s}$. We can exclude losses of ice crystals by sublimation in the simulation due to RHI > $100 \%$ in most regions. Perhaps not all ice particles formed during the jet phase are mixed into the vortices, but create a visible secondary wake, especially for four-engined aircraft. Particle detrainment may be underrepresented in the EULAG-LCM model. Slightly different atmospheric conditions may lead to different vortex dynamics and enhanced detrainment of ice particles. Because of strong dilution at an initial plume age of $20 \mathrm{~s}$, the model is initialized with constant temperature. Buoyancy from still warm exhaust gases inside the plume could increase the detrainment.

In the case of the modelled A319 contrail, larger fractions of ice particles are detrained from the primary vortices than for the modelled A380 contrail. Due to lower aircraft weight and smaller wing span, the primary vortices of the A319 have

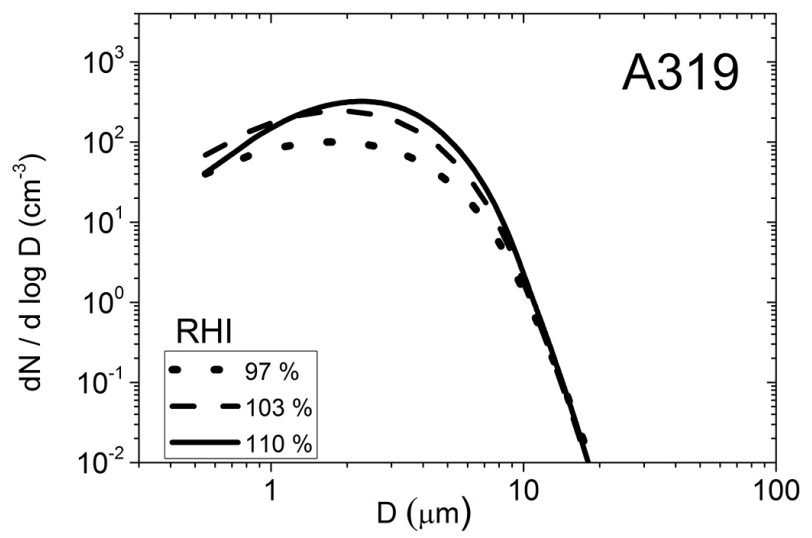

Fig. 7. Particle number concentrations for ambient RHI of $97 / 103 / 110 \%$, respectively. The simulations were performed with the EULAG-LCM model for the A319 aircraft. All parameters but RHI were kept constant. While the total particle number increases for higher RHI, no significant concentration increase is observed for large particles. The increase in particle number density with increasing RHI for diameters within $1 \mu \mathrm{m}$ to $10 \mu \mathrm{m}$ leads to higher values in extinction and optical depth.

already decayed further at a contrail age of $100 \mathrm{~s}$. Due to the breakup of the vortices, the warmed detrained air can rise upwards again buoyantly and cause mixing, extending the ice particle distribution. This feature develops later for the A380 contrail in the model. The two particle size distributions observed in the primary and secondary wake of the contrail of the A380 aircraft are shown in Fig. 8. While the total particle number is similar for both contrail segments, particles tend to be much larger in the secondary wake, leading to higher values for extinction and contrail optical depth. The optical depth distribution depends strongly on the mean vertical contrail extension, which is dependent on the formation of a secondary exhaust plume. Mean values for the extinction of $1.3 \mathrm{~km}^{-1}\left(1.7 \mathrm{~km}^{-1}\right)$ for the A319 aircraft and $1.7 \mathrm{~km}^{-1}\left(2.4 \mathrm{~km}^{-1}\right)$ for the A380 aircraft are calculated for 97 (103) \% RHI, respectively. The computed extinction values are about $30 \%$ below the values derived from the observations. The optical depth is calculated to be 0.09 for the A319 contrail and 0.16 for the A380 contrail. The optical depth still increases for the heavier aircraft, but both values derived from the model calculations are significantly lower than those derived from the observational data. The discrepancy is higher for the A380 aircraft because of the limited development of a secondary wake at $t \approx 100 \mathrm{~s}$ in the model and thus a smaller net vertical contrail extension. The discrepancy can be only partially explained by higher RHI values. The underrepresentation of large particles $(D>7 \mu \mathrm{m})$ in the model also contributes to this effect. A possible overestimation of the number of large particles in the observations due to coincidence effects leading to a broadening of the size distribution may also contribute to the difference. 


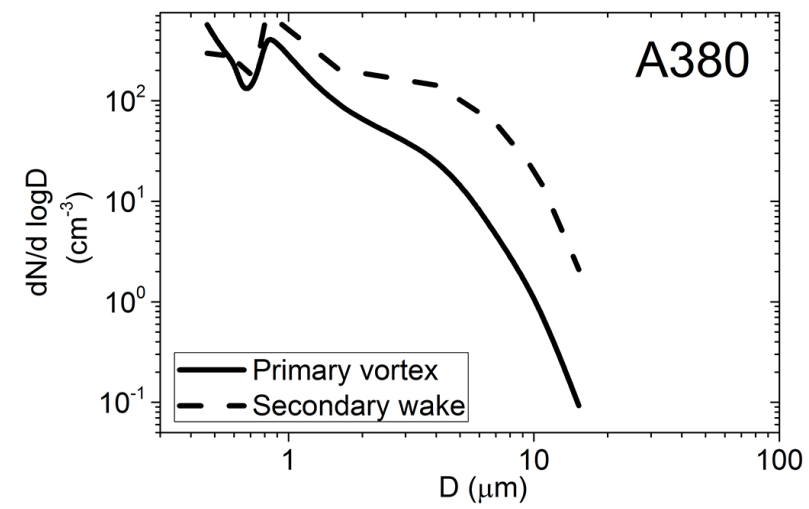

Fig. 8. Particle size distribution observed in the contrail of the A380 aircraft. The secondary wake has been observed between $44182 \mathrm{~s}$ and $44232 \mathrm{~s}$ UTC (see Fig. 2 ) at a contrail age of $\approx 105 \mathrm{~s}$; the primary vortex was also observed between $44112 \mathrm{~s}$ and $44158 \mathrm{~s}$ UTC at a contrail age of $\approx 92 \mathrm{~s}$ on 19 November 2008. Particle concentrations decrease in the primary vortex due to partial particle sublimation of initially larger ice crystals.

\subsection{Bulk model study}

\subsubsection{The CoCiP model}

The contrail properties can be estimated using a bulk ice cirrus model as implemented in CoCiP (Schumann, 2012). The model is based on the following assumptions: all contrail parameters are assumed to be uniform over an effective contrail cross section of ellipsoidal shape and area $A$. All processes are assumed to occur isobarically, and temperature changes due to phase changes are assumed to be negligible. The properties in the measured contrail are assumed to result from a mixture of $N_{\text {dil }}$ mass units of ambient air with the emissions resulting from burning one mass unit of fuel. By definition, the dilution ratio relates any mass-specific concentration $\Delta c$ of passive tracers in the exhaust plume to its emission index EI by $\Delta c=\mathrm{EI} / N_{\mathrm{dil}}$. The humidity $q$ inside the contrail is assumed to be at ice saturation. The ice mass in the contrail results from the humidity from entrained ambient air plus the amount of water emitted from the aircraft after approaching ice saturation. The number of ice particles is taken as proportional to the number of soot particles emitted times an estimated ice particle survival factor $f_{\mathrm{s}}$. The survival factor accounts for particle losses during vortex sinking. The dilution ratio $N_{\text {dil }}$ that CoCiP computes for given aircraft properties, plume age, and thermal stratification, is sensitive to ambient shear, which is not well known from the observations. Therefore, here dilution is instead estimated from the measured $\Delta \mathrm{NO}_{\mathrm{x}}$ (or $\Delta \mathrm{NO}_{\mathrm{y}}$ ) concentration excess above ambience.

For these conditions, the contrail cross-section area $A$, in $\mathrm{m}^{2}$, follows from the dilution ratio $N_{\text {dil }}$ (Schumann et al., 1998), $\rho A=N_{\mathrm{dil}} m_{\mathrm{F}}$,

with $\rho=$ air density, and $m_{\mathrm{F}}$ the fuel consumption per flight distance in $\mathrm{kg} \mathrm{m}^{-1}$. The ice water content $I W C$, in $\mathrm{kg} \mathrm{m}^{-3}$, is

$\mathrm{IWC}=\mathrm{EI}_{\mathrm{H}_{2} \mathrm{O}} m_{\mathrm{F}} / A+\rho\left(q_{0}-q_{\mathrm{s}}\right)$,

with $\mathrm{EI}_{\mathrm{H}_{2} \mathrm{O}}=1.23$, the water vapour emission index for kerosene, $A$ the contrail cross-section area in $\mathrm{m}^{2}, q$ the absolute humidity or water mass mixing ratio in $\mathrm{kg} \mathrm{kg}^{-1}$, and $q_{0}$ the ambient humidity.

The saturation mixing ratio for ice saturation, $q_{\mathrm{sat}}=$ $\left(M_{\mathrm{H}_{2} \mathrm{O}} / M_{\text {air }}\right) p_{\text {ice }}(T) / p$, is a function of the ambient pressure $p$ in $\mathrm{Pa} ; p_{\text {ice }}(T)$ is the ice saturation pressure, $T$ is the ambient air temperature in $\mathrm{K}$, and $M_{\mathrm{H}_{2} \mathrm{O}} / M_{\text {air }}=0.622$ is the molar vapour/air mass ratio. The number of ice particles per flight distance $N_{\text {ice }}$ and the volume-specific particle concentration $n_{\text {ice }}$ are

$N_{\text {ice }}=f_{\mathrm{s}} \mathrm{EI}_{\text {soot }} m_{\mathrm{F}}, n_{\text {ice }}=N_{\text {ice }} / A$.

Here, $\mathrm{EI}_{\text {soot }}$ is the soot particle number emission index, and $f_{\mathrm{S}}$ the survival factor. The volume mean particle size $r_{\mathrm{vol}}$, in $m$, follows from

$N_{\text {ice }} \rho_{\text {ice }} t(4 / 3) \pi\left(r_{\text {vol }}\right)^{3}=$ IWC $A$.

Here, $\rho_{\text {ice }}$ is the ice particle bulk density in $\mathrm{kg} \mathrm{m}^{-3}$ (assumed: $917 \mathrm{~kg} \mathrm{~m}^{-3}$ ). The optically effective radius $r_{\text {eff }}=D_{\text {eff }} / 2$ differs from $r_{\mathrm{vol}}$. The ratio is the factor $\mathrm{C}$ as discussed in Schumann et al. (2011):

$r_{\mathrm{eff}}=r_{\mathrm{vol}} / C$.

The factor ranges typically from 0.6 to 1 and can be determined for the measured cases from the measured values of IWC, number density and effective radius:

$C=\left[\operatorname{IWC} /\left(\rho_{\text {ice }} N_{\text {ice } \pi 4 / 3)}\right]^{1 / 3} / r_{\text {eff }}\right.$.

The measurements (see Table 2) imply $C=0.87,0.77$ and 0.73 , for the three cases. In the following we use $C=0.8$, consistent with other data (Schumann et al., 2011).

The solar radiation extinction coefficient is

$\beta=3 Q_{\text {ext }} \operatorname{IWC} /\left(4 \rho_{\text {ice }} r_{\text {eff }}\right)$,

with $Q_{\text {ext }}=2$ (or a size-dependent value) as solar radiation extinction efficiency.

The optical depth (at solar wavelength, nominally $550 \mathrm{~nm}$ ) over an effective contrail depth $H$ is

$\tau=H \beta$.

For weak ambient shear, the width of the contrail $B$ is of order $(\pi / 2) s$, where $s$ is the span width of the aircraft (in 
agreement with Misaka et al. (2012); see below). The effective (in the sense of representing the optically effective depth of an ellipsoidal contrail cross section; see Schumann, 2012) contrail depth $H$ and effective contrail width $B$ are related to the contrail cross-section area by $A=B H$. For given $A$ and $B$, the effective contrail depth $H$ results from $H=A / B$.

The so-called total extinction is defined as the product of mean extinction times contrail cross section,

$\mathrm{EA}=A \beta=B \tau$.

Finally, one can insert the above equations to obtain a closed solution for the dependence of EA on aircraft and meteorological parameters:

$$
\begin{gathered}
\mathrm{EA}=\left[9 \pi /\left(16 \rho_{\text {ice }}^{2}\right)\right]^{1 / 3} C Q_{\text {ext }} m_{\mathrm{F}}\left[f_{\mathrm{s}} \mathrm{EI}_{\text {soot }}\right]^{1 / 3} \\
{\left[\mathrm{EI}_{\mathrm{H}_{2} \mathrm{O}}+(\mathrm{RHI}-1) N_{\text {dil }} M_{\mathrm{H}_{2} \mathrm{O}} p_{\mathrm{s}}(T) /\left(M_{\text {air }} p\right)\right]^{2 / 3}}
\end{gathered}
$$

for given $\mathrm{RHI}=q / q_{\mathrm{sat}}$. Hence, the total extinction $\mathrm{EA}=A \beta$ scales linearly with both the optical properties $C Q_{\text {ext }}$ of the contrail particles and with the fuel consumption per flight distance $m_{\mathrm{F}}$. In addition, it scales with the third root of the number of ice particles surviving per unit mass of burnt fuel, and the 2/3-root of an expression containing $\mathrm{EI}_{\mathrm{H}_{2} \mathrm{O}}$ and (RHI-1), which is basically the ice water content in the plume per flight distance normalized to fuel consumption. The latter scales with dilution $N_{\text {dil }}$ in ice-supersatured air, ambient relative ice supersaturation (RHI-1), temperature $T$ (because of the saturation pressure $p_{\mathrm{S}}(T)$ ) and the altitude-dependent inverse ambient pressure $p$. The contributions from water vapour engine emissions (measured by $\mathrm{EI}_{\mathrm{H}_{2} \mathrm{O}}$ ) may be important for short-lived and sublimating contrails, but are negligible for large dilution in ice-supersatured air. Aircraft parameters enter this equation mainly via the fuel consumption, the emission index for soot, flight level (ambient pressure), and the aircraft dependence of the dilution. Meteorology enters in terms of temperature, humidity, and ambient parameters controlling dilution $N_{\text {dil }}$ (wind shear, thermal stratification, ambient turbulence). Cloud microphysics and wake dynamics are important for $C, Q_{\text {ext }}$ and the survival factor $f_{\mathrm{s}}$.

\subsubsection{CoCip model results and comparison with observations}

The analysis uses input values as listed in Table 1. The model results depend critically on the assumed dilution value $N_{\text {dil }}$. Strong mixing implies high $N_{\text {dil }}$ and low plume concentrations. In particular, the $\mathrm{NO}_{\mathrm{y}}$ mixing ratio and the particle concentrations become small, and the contrail evaporates early for subsaturated conditions for large dilution. Previous measurements suggest an approximate function $N_{\text {dil }}=7000(t / 1 \mathrm{~s})^{0.8}$ versus plume age $t$, i.e. about $0.30 \times 10^{6}$ for the A319 and A380 aircraft and $0.24 \times 10^{6}$ for the younger A340 aircraft. The approximate function is known to have about a factor of 3 uncertainty (Schumann et al., 1998). The measured $\mathrm{NO}_{\mathrm{y}}$ values are rather low, and suggest larger dilution values of $1.33 \times 10^{6}, 1.40 \times 10^{6}$, and $1.94 \times 10^{6}$ for the A319, A340 and A380 aircraft. On the other hand, the measured particle concentrations are high and suggest lower dilution values. Based on emission index values for $\mathrm{NO}_{\mathrm{x}}$ and soot number, as given in Table 4, either the measured $\mathrm{NO}_{\mathrm{y}}$ concentration is a factor 5 too low or the measured particle concentrations are a factor 5 too high for consistent dilution modelling of $\mathrm{NO}_{\mathrm{y}}$ and particles. Higher soot particle emissions may explain this discrepancy (Schumann et al., 2013).

For better consistency in ice particle properties, the calculations with $\mathrm{CoCiP}$ were performed for small dilution values, and high soot number emission values. Still, even for a factor 5 lower dilution values (implying higher exhaust concentrations), the contrail would fully evaporate when the observed conditions (see Table 1) apply constantly over the whole contrail life time. Hence, larger RHI values are required for consistency of the bulk model and the clearly visible contrail.

\subsubsection{Comparison with the EULAG-LCM model results}

We applied the CoCiP bulk model first with low RHI values of $97 \%$ and $103 \%$, as also used for the EULAG-LCM model (see Table 5). Both models compute a visible contrail for the slightly subsaturated environment $(97 \%)$. The ice particle concentrations and the effective diameters are of the same order of magnitude in both simulations. The $\mathrm{NO}_{\mathrm{y}}$ concentration in the EULAG-LCM model is slightly lower than in CoCiP, suggesting larger dilution factors. The ice particle number density in EULAG-LCM is higher than in the bulk model for the A380 and lower for the A319. The net vertical extension calculated by EULAG-LCM is low due to the limited formation of the secondary wake in the case of the A380. Here, CoCiP computes higher values. The calculated optical depths values agree well between both models for the given RHI (97\% and $103 \%$ ).

For best consistency with the observed ice particle properties, the CoCiP bulk model was also applied using higher dilution values, implying $\mathrm{NO}_{\mathrm{y}}$ mixing ratios as observed for the A319 and twice as high as observed for the A380 case, assuming that the concentration maxima in the primary wake for the large aircraft have been missed or are at least underrepresented due to a focus of the measurements in the secondary wake. The computations were performed for a soot emission index of $1.0 \times 10^{15} \mathrm{~kg}^{-1}$ and an assumed higher relative humidity of $120 \%$. For these conditions, CoCiP matches the observations within a few percent. This is the case in particular for the ice water content, ice particle number density, optical effective diameter, and contrail dimensions in horizontal and vertical directions. The computed extinction and optical depth are higher than deduced from observations by $25-50 \%$ for the A 319 and by $10 \%$ for the A380. 
Table 5. Parameters used in the CoCiP bulk model and model results, in a presentation similar to Table 4.

\begin{tabular}{llrrrrrr}
\hline & unit & A319 & A319 & A319 & A380 & A380 & A380 \\
\hline RHI & $\%$ & 97 & 103 & 120 & 97 & 103 & 120 \\
EI $_{\text {Soot }}$ & $10^{14} \mathrm{~kg}^{-1}$ & 3.23 & 3.23 & 10 & 2.36 & 2.36 & 10 \\
NO $_{\text {y mixing ratio }}$ & $\mathrm{nmol} \mathrm{mol}^{-1}$ & 21.5 & 21.5 & 4.3 & 33.5 & 33.5 & 13.4 \\
Survival factor & & 0.5 & 0.5 & 0.5 & 0.5 & 0.5 & 0.5 \\
\hline Ice water content IWC & $\mathrm{mg} \mathrm{m}^{-3}$ & 1.2 & 2.3 & 4.0 & 0.6 & 1.8 & 4.6 \\
Ice particle concentration $n_{\text {ice }}$ & $\mathrm{cm}^{-3}$ & 234 & 234 & 152 & 117 & 117 & 208 \\
Effective diameter $D_{\text {eff }}$ & $\mu \mathrm{m}_{\text {Vertical extension } H}$ & 2.8 & 3.4 & 4.7 & 2.8 & 4 & 4.5 \\
Horizontal extension $B$ & $\mathrm{~m}$ & 28 & 28 & 137 & 128 & 128 & 305 \\
Optical depth $\tau$ & $\mathrm{m}$ & 53.6 & 53.6 & 54 & 123 & 123 & 125 \\
Mean extinction $\beta$ & & 0.04 & 0.06 & 0.38 & 0.09 & 0.19 & 1.0 \\
& $\mathrm{~km}$ & 1.4 & 2.1 & 2.7 & 0.70 & 1.5 & 3.4 \\
\hline
\end{tabular}

\subsubsection{Importance of aircraft dependence of contrail properties for radiative forcing}

We perform a sensitivity study to investigate the relative radiative effects of two global hypothetical fleets of A380 or A319 aircraft. To this end CoCiP is also applied to simulate the evolution of contrails for given air traffic and meteorology globally. The method and the approach are as described before (Schumann, 2012; Schumann and Graf, 2013; Schumann et al., 2013). The model is not restricted to young contrails, but simulates the full lifecycle of all contrails from formation until dissipation by subsidence or by mixing with ambient dry air, or by particle sedimentation. The global model results, including the full lifecycle of contrails, are used to compute global mean contrail cover and radiative forcing (RF) by contrails. Since contrail cirrus modelling is difficult, these results should be seen as a qualitative indication of the importance of the aircraft impact on contrails. Moreover, the simulation was performed for a three-day period only. The global simulation with this model shows a change in net RF by factors of 0.73 or 2.51 , when the global fleet of aircraft is replaced by a fictive fleet in which all aircraft are either A319 or A380 aircraft, respectively. Hence, the RF is about a factor 3.5 larger for an A380 than for an A319. This change results mainly from the larger aircraft mass (factor 8) and the larger fuel consumption (factor 6). These parameters cause changes in the simulated soot emissions, size-dependent mixing in the aircraft wake, and related contrail properties in the model. Hence, the global contrail effects depend strongly on the aircraft types. In terms of RF per passenger seat or RF per passenger-seat distance, the ratio between the simulation results for different aircraft is closer to unity or even smaller than one, i.e. a larger aircraft may have smaller climate impact per transport unit than a smaller aircraft. This shows the importance of knowing the climate impact of contrails as a basis for selecting the proper aircraft for the respective transport task.

\section{Impact of fuel flow on contrail optical properties}

The observed optical and microphysical properties of the three young contrails are in the range of earlier observations. Lidar measurements by Sussmann and Gierens (2001) report a maximum optical depth of 0.26 for a 5 min-old contrail from the Falcon research aircraft at RHI $=111 \%$, which is in the range of the optical depth derived for the A319 aircraft. The observed extinction coefficients of the contrails are about a factor of 4 higher than previously observed by Febvre et al. (2009) for contrails from a comparatively small Embraer-170 aircraft of similar age. A maximum ice particle number concentration of $420 / 580 / 540 \mathrm{~cm}^{-3}$ was observed in the 2 min-old A319/A340/A380 contrails, which is slightly lower than observed in a less than 1 min-old B757 contrail (Baumgardner and Gandrud, 1998), probably due to increased dilution. The ice particle number concentrations in the 3 contrails agree well with number concentrations of several $100 \mathrm{~cm}^{-3}$, with $D_{\text {eff }}$ between $4 \mu \mathrm{m}$ and $8 \mu \mathrm{m}$ in a less than 3 min-old contrail reported by Schröder et al. (2000). The derived contrail depths of about 110 to $290 \mathrm{~m}$ for the various aircraft is comparable to the depth of $110 \mathrm{~m}$ deduced from ground-based lidar observations by Sassen and Hsueh (1998) for a 2 min-old contrail of a DC8 aircraft (mass about $100 \mathrm{Mg})$.

In order to scale optical contrail properties to unit flight distance, we integrate the extinction over the vertical ellipsoidal contrail cross section (for results see Table 6), whereby the contrail depth is derived from the P2P model (Holzäpfel, 2006) and the contrail width from Misaka et al. (2012) (their Fig. 23). Misaka et al. (2012) performed large eddy simulations to analyse the development of the contrail vertical and horizontal extensions with regard to different atmospheric conditions. For typical ambient temperature stratification and no or weak atmospheric turbulence, represented by their cases $1-3$, the plume width of a passive tracer is nearly constant at a value of $1.9 b_{0}$ in the first minutes of contrail evolution, with $b_{0}$ being the initial vortex spacing. 
Table 6. Contrail properties, total extinction and fuel consumption per unit flight path for 3 different aircraft.

\begin{tabular}{llllll}
\hline Aircraft & $\begin{array}{l}\text { Vertical } \\
\text { depth }(\mathrm{m})\end{array}$ & $\begin{array}{l}\text { Contrail } \\
\text { width }(\mathrm{m})\end{array}$ & $\begin{array}{l}N_{\text {ice }} \\
\left(\mathrm{m}^{-1}\right)\end{array}$ & $\begin{array}{l}\text { Fuel flow } m_{\mathrm{F}} \\
\text { per flight distance } \\
\left(\mathrm{kg} \mathrm{km}^{-1}\right)\end{array}$ & $\begin{array}{l}\text { Total extinction } \\
(\text { extinction } \times \text { contrail } \\
\text { cross section })(\mathrm{m})\end{array}$ \\
\hline A319 & 120 & 51 & $7.73 \times 10^{11}$ & 2.2 & 10 \\
A340 & 220 & 90 & $2.58 \times 10^{12}$ & 6.4 & 39 \\
A380 & 290 & 119 & $6.39 \times 10^{12}$ & 15.9 & 88 \\
\hline
\end{tabular}

Assuming an aerodynamic favourable elliptic lift distribution, $b_{0}$ can be estimated by $\pi / 4$ times wing span of the aircraft. The plume width is close to the estimate $B=(\pi / 2) s$ used in the bulk model (see above).

Interestingly, for 2 min-old contrails near ice saturation, the total extinction EA shows a linear dependence on the fuel flow rate (Fig. 9). The observational data of EA versus fuel flow rate $m_{\mathrm{F}}$ can be fitted by a line with a slope of $5.6\left(\mathrm{~m} \mathrm{~km} \mathrm{~kg}^{-1}\right)$ and a Pearson correlation coefficient $R^{2}$ of 0.989 (standard error of 0.41) (see also Table 5). The linear trend is fully consistent with the bulk model relationship (see Eq. 12), shown in Fig. 9. The absolute values in the bulk model simulations are smaller than in the observations at similar atmospheric background conditions, as discussed above. The extinction measured by the PN is lower than the extinction derived from the FSSP-300. This can be explained by the assumption used in the data analysis that all the particles are spherical at the time of measurement. During contrail aging, particles typically grow more aspherical. However, the difference is still small in young contrails, and the differences between PN and FSSP-300 are within the measurement uncertainties. Additionally, bulk model simulations for $120 \%$ RHI are shown. For comparison, results from Naiman et al. (2011), Sussmann (1999) and Febvre et al. (2009) are shown in Fig. 9, although the atmospheric conditions and aircraft properties differ significantly from our cases. Naiman et al. (2011) calculated the contrail optical depth and contrail width for different aircraft fuel flow rates at $130 \%$ RHI with an initial ice crystal number per fuel burnt of $10^{15} \mathrm{~kg}^{-1}$, and for fixed aircraft fuel flow rate at changing RHI $(110 \%, 120 \%, 130 \%)$. The computed contrail width was about $80 / 100 / 60 / 80 / 80 \mathrm{~m}$, and optical depths about 1.0/1.5/0.75/0.55/0.75 for their contrail cases E/F/G/M/L, respectively (their Fig. 16). The reported total extinction was calculated assuming an ellipsoidal contrail cross section, as in this study. The simulation results also show a linear increase of contrail total extinction with fuel consumption at $130 \%$ RHI, although the absolute values are higher due to higher ice supersaturations. For $110 \%$ RHI the simulation results are close to our observations. Sussmann (1999) observed a 50 s-old contrail from a B747-400 aircraft (weight $345 \mathrm{Mg}$ ) with a lidar instrument. Ambient RHI is unknown, but ice supersaturated conditions are expected because of observed particle growth in the secondary wake. The total ex-

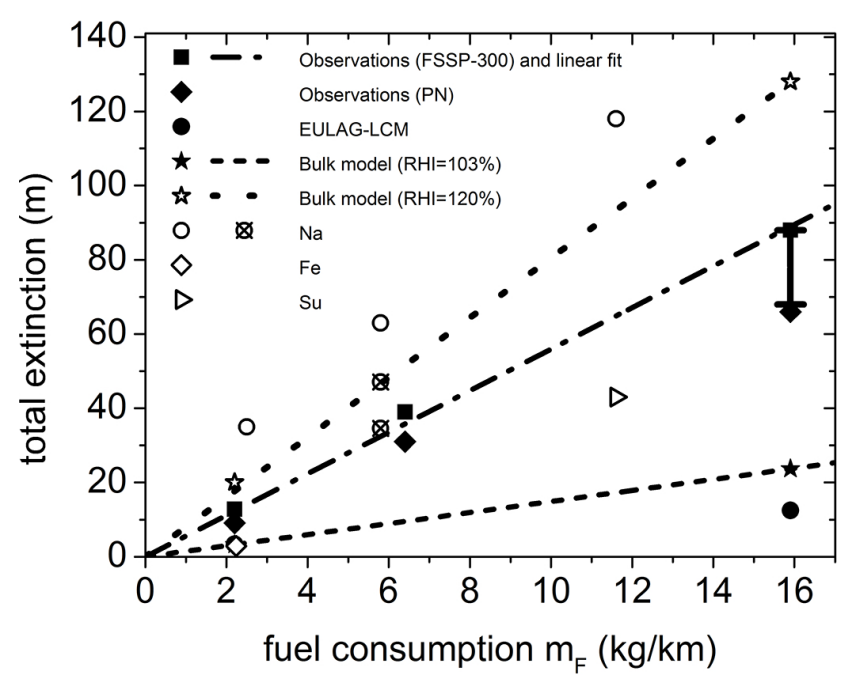

Fig. 9. Total extinction (extinction times contrail cross section) is shown versus the fuel consumption per distance of the contrailproducing airliner. Results from this study are shown in bold symbols. A possible overestimation of the total extinction of the A380 contrail due to a focus of measurements in the secondary wake is shown via the error bar. A linear fit has been applied to the FSSP300 observations with a gradient of $5.6 \mathrm{~m} \mathrm{~km} \mathrm{~kg}^{-1}$ (point-dashed line). In addition, results from polar nephelometer measurements are shown in bold diamond symbols. Differences between FSSP and PN results are explained by different assumptions of particle shape. The results of the bulk model are shown by the dashed (pointed) line with star symbols fitting the fuel consumption of the analysed airliners for RHI $=103 \%(120 \%)$. For comparison, model results from Naiman et al. (2011) (their Fig. 16) are shown by the empty circle symbols (Na). The contrail age is about $100 \mathrm{~s}$, initial RHI are $130 \%$ (empty circles) and $110 \% / 120 \%$ for the crossed circles, with the lower value for $110 \%$. Lidar observations of a 50 s-old contrail of a B747 by Sussmann (1999) are shown by the empty triangle symbol $\mathrm{Su}$. Additionally, the total extinction observed in situ by Febvre et al. (2009) for a young and small contrail is shown by the empty diamond symbol $(\mathrm{Fe})$.

tinction shown is based on an estimated optical thickness of 0.45 (their Fig. 8) and a contrail width of a B747-400 aircraft of $96 \mathrm{~m}$, calculated analogue to the contrail widths in this study. The observations by Febvre et al. (2009), with assumed $50 \mathrm{~m}$ contrail width and $120 \mathrm{~m}$ vertical extension, are 
in good agreement with the EULAG-LCM model results, but lower than observed for the A319 in this study.

\section{Discussion}

A dependence of contrail properties on aircraft type has been modelled previously (Lewellen and Lewellen, 2001; Naiman et al., 2011). Sussmann and Gierens (2001) use model results in combination with lidar observations to discuss contrail properties in relation to the number of aircraft engines. Here, we use state-of-the-art in situ observations in combination with results from two independent models, the EULAGLCM model (Sölch and Kärcher, 2010) and the CoCiP model (Schumann, 2012), to investigate the dependence of contrail properties on aircraft size, weight and fuel flow. In the models, the initial atmospheric conditions are kept constant, while parameters depending on the aircraft type such as wing span, weight, speed, fuel flow, and soot emission index are varied. The observed increase in ice crystal number and contrail optical depth with increasing aircraft weight is generally confirmed with the EULAG-LCM model, although details depend strongly on ambient humidity, as expected. The bulk model also computes an increase in optical depth with fuel flow. In addition, we find no significant differences in particle sizes of 2 min-old contrails from different aircraft, both in the observations and in the models.

The EULAG-LCM model underestimates the ice crystal number density in the secondary wake outside the primary vortices significantly, particularly for the A380 aircraft at $t=110 \mathrm{~s}$. This might be an effect of complex turbulent mixing processes, which are a challenge to be accurately represented in models. We may speculate, especially in the case of a 4-engine aircraft, that not all ice particles are entrained into the primary wake, leading to an early formation of a secondary wake structure containing ice particles. Also, the soot emission index used in the model to define the initial ice crystal number is a rough estimate and may be underestimated (Schumann et al., 2013). Larger initial ice crystal numbers leading to higher ice crystal number densities in the contrail are possible and would lead to higher total particle numbers in primary and secondary wakes. However, this would not affect the percentage of particles being mixed out of the primary vortices. In addition, there is a discrepancy in the representation of large particles $(D>10 \mu \mathrm{m})$ between observations and EULAG-LCM model results. This may give hints to an inaccurate representation of the initial ice crystal size distribution in the model. Larger ice particles may form at the outer edge of the contrail, with low soot concentrations but high humidity from mixing with supersaturated ambient air. Instrumental oversampling or oversizing of low particle concentrations at the large-size end of the FSSP-300 sampling range may also have contributed to the differences. The optical contrail properties are dominated by the large fraction of particles in the size range 3 to $13 \mu \mathrm{m}$. Ice particles larger than $13 \mu \mathrm{m}$ contribute less than $5 \%$ to total surface area, and are therefore of minor importance for the optical depth. The relevant size range may increase for higher ambient humidity and higher temperatures.

The bulk model provides good agreement with the observations, in particular of ice water content, if the ambient RHI is increased by $\sim 7$ to $15 \%$ compared to the observed value. Such high values are still within the range of instrumental uncertainties of the humidity and temperature measurements. In the EULAG-LCM model, the computed particle diameters and optical depths increase with RHI by stronger water vapour uptake. For RHI $=110 \%$, they still do not reach the observation-derived values. An even higher ambient RHI of about $120 \%$ would be required to explain the ice water content and optical depth derived from the observations. Overall, the measurements and simulations show significant differences with respect to secondary contrail formation, relative humidity and particle sizes, which indicate a need for further aircraft campaigns.

The comparison of the EULAG-LCM and CoCiP results shows that the bulk model results are of the same order of magnitude as those of the detailed, process-oriented EULAG-LCM model. Both models compute a visible contrail for a slightly ice subsaturated environment (97\%). Also, the calculated effective particle diameters and the ice particle number densities are similar in both models, and both show a dependence on aircraft size. The bulk model suggests an increase in total extinction, with $\left[N_{\mathrm{dil}}(\mathrm{RHI}-1)\right]^{2 / 3}$ for higher supersaturation and large dilution when the contribution from the emitted water has become small. Hence, further contrail evolution is largely influenced by dilution (wind shear, ambient stratification and ambient turbulence) and ambient RHI fields. Changes in microphysical contrail properties will then occur and will change the factor $C Q_{\text {ext }}$, which depends on particle habit and size distribution (Schumann et al., 2011). The further evolution also depends on formation and loss of ice particles, i.e. the effective survival factor. The aircraft effects on contrail properties remain notable at least up to contrail ages of tens of minutes (Lewellen and Lewellen, 2001; Naiman et al., 2011), and influence the characteristics of contrail cirrus on an even longer time scale, in agreement with Unterstrasser and Gierens (2010).

\section{Conclusions and outlook}

In situ observations of young contrails were used to investigate the dependence of contrail properties on the aircraft type. Contrails with ages less than 2 min from A319-111, A340-311 and A380-841 aircraft were probed with the Falcon research aircraft during the CONCERT2008 campaign under similar meteorological conditions (pressure, ambient RHI, temperature, stable stratification, low shear, at temperatures well below contrail formation threshold values). Under these conditions, an increase in ice particle number density 
and contrail vertical depth is observed with increasing aircraft weight, yielding a factor of 3 higher optical depths for the heavier aircraft ( $\tau$ range 0.25 to 0.94 ). Interestingly, effective particle diameters of the 3 contrails were similar within the experimental uncertainties, with RHI near ice saturation.

Simulations with two independent models were used to investigate the dependence of contrail properties on aircraft size. In the models, the initial atmospheric conditions are kept constant while aircraft-dependent parameters are chosen to match the observed cases. The increasing trend in ice crystal number density and contrail optical depth with increasing aircraft weight is confirmed by the model results, yet generally for smaller $\tau$, possibly due to underrepresented turbulent mixing processes in the models. The contrail properties also show a strong dependence on ambient RHI, as expected. A global CoCiP simulation shows large effects in global contrail radiative forcing for model initializations with two fictive fleets of A319 or A380 type aircraft only, suggesting sensitivity of global contrail parameters to the aircraft type throughout the contrail lifetime. For aged contrails, in situ observational data to confirm the effect of the aircraft type on contrail parameters are not available. An analytical formulation is derived from the bulk model; see Eq. (12). It explains the observed dependence of contrail properties on aircraft type by higher fuel consumption per unit flight distance of the larger aircraft and therefore higher emissions, particularly of water vapour and soot. In addition, a deeper descent of the vortices and therefore a larger contrail extension contributes significantly to the increase in contrail optical depth. The total extinction (extinction $\times$ contrail cross section) scales linearly with the fuel flow per flight distance in model simulations and observations. A non-linear dependence on RHI is predicted by the bulk model.

The observational results shown in this study are obtained for the observed meteorological conditions with RHI close to ice saturation. The contrail properties may vary for different meteorological conditions, especially regarding ambient relative humidity and thermal stratification. For older contrails, wind shear may also influence the contrail properties. Further observations in contrails under different meteorological conditions would be helpful to confirm the dependence of the total extinction on aircraft and atmospheric parameters, especially at higher ambient relative humidity, at different temperatures, and in aged contrails. Such relationships would be important as input for detailed contrail models. They might also be used to initialize contrail parameters in regional and global models without resolving the small-scale contrail dynamics in the wake vortex period, as the aircraft type and fuel flow are often given in aircraft emission inventories.
Acknowledgements. The CONCERT campaign was organized by HGF junior research group AEROTROP (VH-NG-309) and financed within DLR project CATS. This work was funded by contract VO1504/2-1 within DFG SPP HALO 1294. We thank DLR-FX and air traffic control in Germany and Maastricht for excellent support during the campaign. The Deutsche Lufthansa extensively supported the flights and arranged for coordinated flights of the A340 (MOZAIC) aircraft and the A319. We thank M. Krämer for providing humidity data and discussions, T. Hamburger for FSSP-300 instrument preparation, and S. Unterstrasser and K. Gierens for helpful discussions. The EULAG simulations were performed at the Deutsches Klimarechenzentrum (Hamburg) and the Leibniz-Rechenzentrum (Munich). The authors are grateful to D. Baumgardner and the anonymous reviewer for their helpful comments.

The service charges for this open access publication have been covered by a research centre of the Helmholtz Association.

Edited by: T. Butler

\section{References}

Anderson, B. E., Cofer, W. R., Bagwell, D. R., Barrick, J. W., Hudgins, C. H., and Brunke, K. E.: Airborne observations of aircraft aerosol emissions I: Total nonvolatile particle emission indices, Geophys. Res. Lett., 25, 1689-1692, doi:10.1029/98GL00063, 1998.

Baumgardner, D. and Gandrud, B. E.: A comparison of the microphysical and optical properties of particles in an aircraft contrail and mountain wave cloud, Geophys. Res. Lett., 25, 1129-1132, doi:10.1029/98GL00035, 1998.

Baumgardner, D., Dye, J. E., and Gandrud, B. W.: Calibration of the Forward Scattering Spectrometer Probe Used on the ER-2 During the Airborne Antarctic Ozone Experiment, J. Geophys. Res.Atmos., 94, 16475-16480, doi:10.1029/JD094iD14p16475, 1989.

Baumgardner, D., Dye, J. E., Gandrud, B. W., and Knollenberg, R. G.: Interpretation of measurements made by the forward scattering spectrometer probe (FSSP-300) during the airborne arctic stratospheric expedition, J. Geophys. Res.-Atmos., 97, 80358046, doi:10.1029/91JD02728, 1992.

Borrmann, S., Luo, B., and Mishchenko, M.: Application of the T-MATRIX method to the measurement of aspherical (ellipsoidal) particles with forward scattering optical particle counters, J. Aerosol Sci., 31, 789-799, 2000.

Burkhardt, U. and Kärcher, B.: Global radiative forcing from contrail cirrus, Nat. Clim. Change, 1, 54-58, doi:10.1038/NCLIMATE1068, 2011.

Cooper, W. A.: Effects of coincidence on measurements with a forward scattering spectrometer probe, J. Atmos. Ocean. Tech., 5, 823-832, doi:10.1175/15200426(1988)005<0823:eocomw>2.0.co;2, 1988.

Döpelheuer, A.: Anwendungsorientierte Vefahren zur Bestimmung von $\mathrm{CO}, \mathrm{HC}$ und Ruß aus Luftfahrttriebwerken, Deutsches Zentrum für Luft- und Raumfahrt, FB 2002-10, Cologne, 109, 2002.

Döpelheuer, A. and Lecht, M.: Influence of engine performance on emission characteristics, in, Canada Communication Group. Inc., 
Gas Turbine Engine Combustion, Emissions and Alternative Fuels, 11, 1999.

Eyers, C. J., Norman, P., Middel, J., Plohr, M., Michot, S., Atkinson, K., and Christou, R. A.: AERO2k Emissions Inventories for 2002 and 2025, QINETIQ Ltd, 2004.

Fahey, D. W., Schumann, U., Ackerman, S., Artaxo, P., Boucher, O., Danilin, M. Y., Kärcher, B., Minnis, P., Nakajima, T., and Toon, O. B.: Aviation-Produced Aerosols and Cloudiness, Cambridge University Press New York, Aviation and the Global Atmosphere. A Special Report of IPCC Working Groups I and III, edited by: Penner, J. E., Lister, D. H., Griggs, D. J., Dokken, D. J., and McFarland, M., 65-120, 1999.

Febvre, G., Gayet, J.-F., Minikin, A., Schlager, H., Shcherbakov, V., Jourdan, O., Busen, R., Fiebig, M., Kärcher, B., and Schumann, U.: On optical and microphysical characteristics of contrails and cirrus, J. Geophys. Res.-Atmos., 114, D02204, doi:10.1029/2008JD010184, 2009.

Gao, R. S., Fahey, D. W., Popp, P. J., Marcy, T. P., Herman, R. L., Weinstock, E. M., Smith, J. B., Sayres, D. S., Pittman, J. V., Rosenlof, K. H., Thompson, T. L., Bui, P. T., Baumgardner, D. G., Anderson, B. E., Kok, G., and Weinheimer, A. J.: Measurements of relative humidity in a persistent contrail, Atmos. Environ., 40, 1590-1600, doi:10.1016/j.atmosenv.2005.11.021, 2006.

Gayet, J. F., Crépel, O., Fournol, J. F., and Oshchepkov, S.: A new airborne polar Nephelometer for the measurements of optical and microphysical cloud properties. Part I: Theoretical design, Ann. Geophys., 15, 451-459, doi:10.1007/s00585-997-0451-1, 1997.

Gayet, J.-F., Asano, S., Yamazaki, A., Uchiyama, A., Sinyuk, A., Jourdan, O., and Auriol, F.: Two case studies of winter continental-type water and mixed-phase stratocumuli over the sea 1. Microphysical and optical properties, J. Geophys. Res.Atmos., 107, 4569, doi:10.1029/2001JD001106, 2002.

Gayet, J.-F., Shcherbakov, V., Voigt, C., Schumann, U., Schäuble, D., Jessberger, P., Petzold, A., Minikin, A., Schlager, H., Dubovik, O., and Lapyonok, T.: The evolution of microphysical and optical properties of an A380 contrail in the vortex phase, Atmos. Chem. Phys., 12, 6629-6643, doi:10.5194/acp-12-66292012, 2012.

Gerz, T. and Ehret, T.: Wingtip vortices and exhaust jets during the jet regime of aircraft wakes, Aerosp. Sci. Technol., 1, 463-474, doi:10.1016/S1270-9638(97)90008-0, 1997.

Grabowski, W. W. and Smolarkiewicz, P. K.: A Multiscale Anelastic Model for Meteorological Research, Mon. Weather Rev., 130, 939-956, doi:10.1175/15200493(2002)130<0939:AMAMFM>2.0.CO;2, 2002.

Graf, K., Schumann, U., Mannstein, H., and Mayer, B.: Aviation induced diurnal North Atlantic cirrus cover cycle, Geophys. Res. Lett., 39, L16804, doi:10.1029/2012GL052590, 2012.

Greene, G. C.: An approximate model of vortex decay in the atmosphere, J. Aircraft, 23, 566-573, 1986.

Heymsfield, A., Baumgardner, D., DeMott, P., Forster, P., Gierens, K., and Karcher, B.: Contrail Microphysics, B. Am. Meteorol. Soc., 91, 465-472, doi:10.1175/2009BAMS2839.1, 2010.

Holzäpfel, F.: Probabilistic two-phase wake vortex decay and transport model, J. Aircraft, 40, 323-331, 2003.

Holzäpfel, F.: Probabilistic two-phase aircraft wake-vortex model: Further development and assessment, J. Aircraft, 43, 700-708, 2006.
Iwabuchi, H., Yang, P., Liou, K. N., and Minnis, P.: Physical and optical properties of persistent contrails: Climatology and interpretation, J. Geophys. Res.-Atmos., 117, D06215, doi:10.1029/2011JD017020, 2012.

Jensen, E. J., Ackerman, A. S., Stevens, D. E., Toon, O. B., and Minnis, P.: Spreading and growth of contrails in a sheared environment, J. Geophys. Res.-Atmos., 103, 31557-31567, doi:10.1029/98jd02594, 1998.

Jones, H. M., Haywood, J., Marenco, F., O’Sullivan, D., Meyer, J., Thorpe, R., Gallagher, M. W., Krämer, M., Bower, K. N., Rädel, G., Rap, A., Woolley, A., Forster, P., and Coe, H.: A methodology for in-situ and remote sensing of microphysical and radiative properties of contrails as they evolve into cirrus, Atmos. Chem. Phys., 12, 8157-8175, doi:10.5194/acp-12-8157-2012, 2012.

Jurkat, T., Voigt, C., Arnold, F., Schlager, H., Aufmhoff, H., Schmale, J., Schneider, J., Lichtenstern, M., and Dörnbrack, A.: Airborne stratospheric ITCIMS-measurements of $\mathrm{SO}_{2}, \mathrm{HCl}$, and $\mathrm{HNO}_{3}$ in the aged plume of volcano Kasatochi, J. Geophys. Res., 115, D00L17, doi:10.1029/2010JD013890, 2010.

Jurkat, T., Voigt, C., Arnold, F., Schlager, H., Kleffmann, J., Aufmhoff, H., Schauble, D., Schaefer, M., and Schumann, U.: Measurements of $\mathrm{HONO}, \mathrm{NO}, \mathrm{NO}_{\mathrm{y}}$ and $\mathrm{SO}_{2}$ in aircraft exhaust plumes at cruise, Geophys. Res. Lett., 38, L10807, doi:10.1029/2011GL046884, 2011.

Kärcher, B. and Yu, F.: Role of aircraft soot emissions in contrail formation, Geophys. Res. Lett., 36, L01804, doi:10.1029/2008GL036649, 2009.

Korolev, A., Emery, E., and Creelman, K.: Modification and Tests of Particle Probe Tips to Mitigate Effects of Ice Shattering, J. Atmos. Ocean. Tech., 30, 690-708, 2013.

Kübbeler, M., Hildebrandt, M., Meyer, J., Schiller, C., Hamburger, Th., Jurkat, T., Minikin, A., Petzold, A., Rautenhaus, M., Schlager, H., Schumann, U., Voigt, C., Spichtinger, P., Gayet, J.-F., Gourbeyre, C., and Krämer, M.: Thin and subvisible cirrus and contrails in a subsaturated environment, Atmos. Chem. Phys., 11, 5853-5865, doi:10.5194/acp-11-5853-2011, 2011.

Lee, D. S., Fahey, D. W., Forster, P. M., Newton, P. J., Wit, R. C. N., Lim, L. L., Owen, B., and Sausen, R.: Aviation and global climate change in the 21 st century, Atmos. Environ., 43, 3520 3537, doi:10.1016/j.atmosenv.2009.04.024, 2009.

Lewellen, D. C. and Lewellen, W. S.: The effects of aircraft wake dynamics on contrail development, J. Atmos. Sci., 58, 390-406, doi:10.1175/1520-0469(2001)058<0390:TEOAWD>2.0.CO;2, 2001.

McFarquhar, G. M., Zhang, G., Poellot, M. R., Kok, G. L., McCoy, R., Tooman, T., Fridlind, A., and Heymsfield, A. J.: Ice properties of single-layer stratocumulus during the Mixed-Phase Arctic Cloud Experiment: 1. Observations, J. Geophys. Res.-Atmos., 112, D24201, doi:10.1029/2007JD008633, 2007.

Meerkötter, R., Schumann, U., Doelling, D. R., Minnis, P., Nakajima, T., and Tsushima, Y.: Radiative forcing by contrails, Ann. Geophys. Atm. Hydr., 17, 1080-1094, 1999.

Meilinger, S. K., Tsias, A., Dreiling, V., Kuhn, M., Feigl, C., Ziereis, H., Schlager, H., Curtius, J., Sierau, B., Arnold, F., Zoger, M., Schiller, C., and Peter, T.: $\mathrm{HNO}_{3}$ partitioning in cirrus clouds, Geophys. Res. Lett., 26, 2207-2210, doi:10.1029/1999GL900423, 1999.

Minnis, P., Schumann, U., Doelling, D. R., Gierens, K. M., and Fahey, D. W.: Global distribution of contrail 
radiative forcing, Geophys. Res. Lett., 26, 1853-1856, doi:10.1029/1999GL900358, 1999.

Misaka, T., Holzapfel, F., Hennemann, I., Gerz, T., Manhart, M., and Schwertfirm, F.: Vortex bursting and tracer transport of a counter-rotating vortex pair, Phys. Fluids, 24, 025104, doi:10.1063/1.3684990, 2012.

Naiman, A. D., Lele, S. K., and Jacobson, M. Z.: Large eddy simulations of contrail development: Sensitivity to initial and ambient conditions over first twenty minutes, J. Geophys. Res.-Atmos., 116, D21208, doi:10.1029/2011JD015806, 2011.

Paoli, R., Laporte, F., Cuenot, B., and Poinsot, T.: Dynamics and mixing in jet/vortex interactions, Phys. Fluids, 15, 1843-1860, doi:10.1063/1.1575232, 2003.

Petzold, A., Busen, R., Schröder, F. P., Baumann, R., Kuhn, M., Ström, J., Hagen, D. E., Whitefield, P. D., Baumgardner, D., Arnold, F., Borrmann, S., and Schumann, U.: Near-field measurements on contrail properties from fuels with different sulfur content, J. Geophys. Res., 102, 29867-29880, 1997.

Petzold, A., Döpelheuer, A., Brock, C. A., and Schröder, F.: In situ observations and model calculations of black carbon emission by aircraft at cruise altitude, J. Geophys. Res.-Atmos., 104, 2217122181, doi:10.1029/1999JD900460, 1999.

Petzold, A., Fiebig, M., Fritzsche, L., Stein, C., Schumann, U., Wilson, C. W., Hurley, C. D., Arnold, F., Katragkou, E., Baltensperger, U., Gysel, M., Nyeki, S., Hitzenberger, R., Giebl, H., Hughes, K. J., Kurtenbach, R., Wiesen, P., Madden, P., Puxbaum, H., Vrchoticky, S., and Wahl, C.: Particle emissions from aircraft engines a survey of the European project PartEmis, Metereol. Z., 14, 465-476, doi:10.1127/0941-2948/2005/0054, 2005.

Poellot, M. R., Arnott, W. P., and Hallett, J.: In situ observations of contrail microphysics and implications for their radiative impact, J. Geophys. Res.-Atmos., 104, 12077-12084, doi:10.1029/1999JD900109, 1999.

Sassen, K. and Hsueh, C. Y.: Contrail properties derived from highresolution polarization lidar studies during SUCCESS, Geophys. Res. Lett., 25, 1165-1168, doi:10.1029/97g103503, 1998.

Schäuble, D., Voigt, C., Kärcher, B., Stock, P., Schlager, H., Krämer, M., Schiller, C., Bauer, R., Spelten, N., de Reus, M., Szakáll, M., Borrmann, S., Weers, U., and Peter, Th.: Airborne measurements of the nitric acid partitioning in persistent contrails, Atmos. Chem. Phys., 9, 8189-8197, doi:10.5194/acp-9-8189-2009, 2009.

Schiller, C., Krämer, M., Afchine, A., Spelten, N., and Sitnikov, N.: Ice water content of Arctic, midlatitude, and tropical cirrus, J. Geophys. Res.-Atmos., 113, D24208, doi:10.1029/2008JD010342, 2008.

Schmale, J., Schneider, J., Jurkat, T., Voigt, C., Kalesse, H., Rautenhaus, M., Lichtenstern, M., Schlager, H., Ancellet, G., Arnold, F., Gerding, M., Mattis, I., Wendisch, M., and Borrmann, S.: Aerosol layers from the 2008 eruptions of Mount Okmok and Mount Kasatochi: In situ upper troposphere and lower stratosphere measurements of sulfate and organics over Europe, J. Geophys. Res.-Atmos., 115, D00L07, doi:10.1029/2009JD013628, 2010.

Schröder, F., Kärcher, B., Duroure, C., Ström, J., Petzold, A., Gayet, J. F., Strauss, B., Wendling, P., and Borrmann, S.: On the Transition of Contrails into Cirrus Clouds, J. Atmos. Sci., 57, 464-480, doi:0.1175/1520-0469(2000)057<0464:OTTOCI>2.0.CO;2, 2000 .
Schulte, P., Schlager, H., Ziereis, H., Schumann, U., Baughcum, S. L., and Deidewig, F.: $\mathrm{NO}_{\mathrm{x}}$ emission indices of subsonic longrange jet aircraft at cruise altitude: In situ measurements and predictions, J. Geophys. Res., 102, 21431-21442, 1997.

Schumann, U.: On conditions for contrail formation from aircraft exhausts, Meteorol. Z., 5, 4-23, 1996.

Schumann, U.: Influence of propulsion efficiency on contrail formation, Aerosp. Sci. Technol., 4, 391-401, doi:10.1016/S12709638(00)01062-2, 2000.

Schumann, U.: A contrail cirrus prediction model, Geosci. Model Dev., 5, 543-580, doi:10.5194/gmd-5-543-2012, 2012.

Schumann, U. and Graf, K.: Aviation-induced cirrus and radiation changes at diurnal timescales, J. Geophys. Res.-Atmos., 118, 2404-2421, doi:10.1002/jgrd.50184, 2013.

Schumann, U., Schlager, H., Arnold, F., Baumann, R., Haschberger, P., and Klemm, O.: Dilution of aircraft exhaust plumes at cruise altitudes - In situ measurements and predictions, Atmos. Environ., 32, 3097-3103, 1998.

Schumann, U., Busen, R., and Plohr, M.: Experimental test of the influence of propulsion efficiency on contrail formation, J. Aircraft, 37, 1083-1087, 2000.

Schumann, U., Arnold, F., Busen, R., Curtius, J., Kärcher, B., Kiendler, A., Petzold, A., Schlager, H., Schröder, F., and Wohlfrom, K. H.: Influence of fuel sulfur on the composition of aircraft exhaust plumes: The experiments SULFUR 1-7, J. Geophys. Res.-Atmos., 107, doi:10.1029/2001JD000813, 2002.

Schumann, U., Mayer, B., Gierens, K., Unterstrasser, S., Jessberger, P., Petzold, A., Voigt, C., and Gayet, J. F.: Effective radius of ice particles in cirrus and contrails, J. Atmos. Sci., 68, 300-321, doi:10.1175/2010JAS3562.1, 2011.

Schumann, U., Jessberger, P., and Voigt, C.: Contrail ice particles in aircraft wakes and their climatic importance, Geophys. Res. Lett., 40, 2867-2872, doi:10.1002/grl.50539, 2013.

Sölch, I. and Kärcher, B.: A large-eddy model for cirrus clouds with explicit aerosol and ice microphysics and Lagrangian ice particle tracking, Q. J. Roy Meteor. Soc., 136, 2074-2093, doi:10.1002/qj.689, 2010.

Solomon, S., Qin, D., Manning, M., Chen, Z., Marquis, M., Averyt, K. B., Tignor, M., and Miller, H. L.: Contribution of Working Group I to the Fourth Assessment Report of the Intergovernmental Panel on Climate Change, 2007 Cambridge University Press, Cambridge, New York, 2007.

Stettler, M. E. J., Boies, A. M., Petzold, A., and Barrett, S. R. H.: Global civil aviation black carbon emissions, Environ. Sci. Technol., 47, 10397-10404, doi:10.1021/es401356v, 2013.

Sussmann, R.: Vertical dispersion of an aircraft wake: Aerosollidar analysis of entrainment and detrainment in the vortex regime, J. Geophys. Res.-Atmos., 104, 2117-2129, doi:10.1029/1998JD200033, 1999.

Sussmann, R. and Gierens, K. M.: Lidar and numerical studies on the different evolution of vortex pair and secondary wake in young contrails, J. Geophys. Res.-Atmos., 104, 2131-2142, doi:10.1029/1998JD200034, 1999.

Sussmann, R. and Gierens, K. M.: Differences in early contrail evolution of two-engine versus four-engine aircraft: Lidar measurements and numerical simulations, J. Geophys. Res.-Atmos., 106, 4899-4911, doi:10.1029/2000JD900533, 2001. 
Unterstrasser, S. and Gierens, K.: Numerical simulations of contrail-to-cirrus transition - Part 2: Impact of initial ice crystal number, radiation, stratification, secondary nucleation and layer depth, Atmos. Chem. Phys., 10, 2037-2051, doi:10.5194/acp-102037-2010, 2010.

Unterstrasser, S. and Sölch, I.: Study of contrail microphysics in the vortex phase with a Lagrangian particle tracking model, Atmos. Chem. Phys., 10, 10003-10015, doi:10.5194/acp-1010003-2010, 2010.

Voigt, C., Schlager, H., Roiger, A., Stenke, A., de Reus, M., Borrmann, S., Jensen, E., Schiller, C., Konopka, P., and Sitnikov, N.: Detection of reactive nitrogen containing particles in the tropopause region - evidence for a tropical nitric acid trihydrate (NAT) belt, Atmos. Chem. Phys., 8, 7421-7430, doi:10.5194/acp-8-7421-2008, 2008.
Voigt, C., Schumann, U., Jurkat, T., Schäuble, D., Schlager, H., Petzold, A., Gayet, J.-F., Krämer, M., Schneider, J., Borrmann, S., Schmale, J., Jessberger, P., Hamburger, T., Lichtenstern, M., Scheibe, M., Gourbeyre, C., Meyer, J., Kübbeler, M., Frey, W., Kalesse, H., Butler, T., Lawrence, M. G., Holzäpfel, F., Arnold, F., Wendisch, M., Döpelheuer, A., Gottschaldt, K., Baumann, R., Zöger, M., Sölch, I., Rautenhaus, M., and Dörnbrack, A.: In-situ observations of young contrails - overview and selected results from the CONCERT campaign, Atmos. Chem. Phys., 10, 90399056, doi:10.5194/acp-10-9039-2010, 2010.

Voigt, C., Schumann, U., Jessberger, P., Jurkat, T., Petzold, A., Gayet, J. F., Krämer, M., Thornberry, T., and Fahey, D. W.: Extinction and optical depth of contrails, Geophys. Res. Lett., 38, L11806, doi:10.1029/2011GL046884, 2011. 